\title{
Observations of Turbulence within a Natural Surf Zone
}

\author{
B. G. RUESSINK \\ Department of Physical Geography, Faculty of Geosciences, Institute for Marine and Atmospheric Research, \\ Utrecht University, Utrecht, Netherlands
}

(Manuscript received 11 March 2010, in final form 10 August 2010)

\begin{abstract}
Here, the Reynolds stresses $\left\langle u^{\prime} w^{\prime}\right\rangle$ and $\left\langle v^{\prime} w^{\prime}\right\rangle$, where $u^{\prime}, v^{\prime}$, and $w^{\prime}$ are the cross-shore, alongshore, and vertical turbulence velocities, respectively, and the angle brackets represent time averaging, are used to diagnose turbulence dynamics beneath natural breaking surf-zone waves. The data were collected at Truc Vert Beach, France, during a 12-day period in 1-3-m water depth with strong cross-shore and alongshore currents under high-energy wave conditions (offshore significant wave heights ranged between 2 and $8 \mathrm{~m}$ ). The $\left\langle u^{\prime} w^{\prime}\right\rangle$ term is predominantly negative, increases with the ratio of wave height $H_{s}$ to water depth $h(\sim$ degree of wave breaking), and decreases in magnitude toward the bed. This supports the view that the cross-shore shear stress is due to breaking-induced vortices that transport high-speed cross-shore flow downward and disintegrate close to the bed. The occasional positive sign of $\left\langle u^{\prime} w^{\prime}\right\rangle$ within the lower $15 \%-20 \%$ of the water column indicates that sometimes surface-generated turbulence is overwhelmed by bed-generated turbulence, but the conditions when this happens are not clear from the data. The term $\left\langle v^{\prime} w^{\prime}\right\rangle$ is persistently of opposite sign to the alongshore mean current and decreases with height above the seabed, implying that $\left\langle v^{\prime} w^{\prime}\right\rangle$ is due to bottom boundary layer processes rather than surface-generated turbulence. The bottom drag coefficient amounted to $1.6 \times 10^{-3}$, similar to earlier observations. As in other high-Reynolds-number geophysical flows, time series of $u^{\prime} w^{\prime}$ and $v^{\prime} w^{\prime}$ comprise intermittently large, short-duration (here, $\sim 1 \mathrm{~s}$ ) stress events that in the data contribute considerably to the net stress in only $3 \%-15 \%$ of the time. The data further show that the turbulent kinetic energy is depth uniform and increases with $H_{s} / h$. The depth-averaged Froudescaled turbulent kinetic energy beneath surf-zone bores is 0.025 , a factor of 2 to 3 less than observed beneath regular laboratory waves.
\end{abstract}

\section{Introduction}

The surf zone on a gently sloping beach is a region of strong turbulent motion. Both wave breaking and the near-bed vertical shear in cross-shore and alongshore mean flows generate turbulence. In the open ocean, breaking-wave-induced turbulence can extend beneath the surface to several times the wave height (e.g., Terray et al. 1996). The surf zone is generally two to three wave heights deep, implying that breaking-wave-induced turbulence should be able to penetrate all the way to the sea bed. Indeed, the potential of breaking wave turbulence to entrain sediment has been observed in the laboratory (Nadaoka et al. 1988; Okayasu et al. 2002)

Corresponding author address: B. Gerben Ruessink, Department of Physical Geography, Faculty of Geosciences, Institute for Marine and Atmospheric Research, Utrecht University, P.O. Box 80.115, 3508 TC Utrecht, Netherlands.

E-mail: g.ruessink@geo.uu.nl and suggested from field observations (e.g., Voulgaris and Collins 2000; Aagaard and Hughes 2010) and numerical models (Mocke 2001). Many models of sediment transport, however, relate the entrainment of sediment from the sea bed to bed-generated turbulence. Also, limited field observations of Reynolds stresses (Trowbridge and Elgar 2001) beneath breaking waves in the presence of strong $\left(>1 \mathrm{~m} \mathrm{~s}^{-1}\right)$ alongshore currents and their modeling by a surf-zone-modified two-equation turbulence model (Feddersen and Trowbridge 2005) showed no evidence for breaking-wave-induced turbulence at about $1 \mathrm{~m}$ above the bed in $4.5-\mathrm{m}$ mean water depth. The turbulence dynamics beneath breaking waves is thus poorly understood.

Most of our existing knowledge on turbulence due to wave breaking is based on laboratory experiments with periodic waves and without alongshore currents. In a laboratory surf zone with periodic spilling breakers, Nadaoka et al. (1989) observed how, below the twodimensional horizontal surface roller, the turbulent flow 
field transforms into three-dimensional eddies that extend obliquely downward. In the water column, these obliquely descending eddies (ODEs) quickly break up into incoherent, three-dimensional turbulence. Some ODEs may, however, survive through the entire water column to impinge on the seabed and suspend sediment. As the turbulence beneath a spilling breaker has not dissipated completely by the time of arrival of the next wave (Ting and Kirby 1995, 1996), the remaining turbulence will interact with the turbulence flow field beneath the next/following wave. As a consequence, the ODE size and location will vary from wave to wave, causing the turbulent flow field, even under periodic laboratory waves, to be strongly intermittent in both time and space (Cox and Kobayashi 2000). Within an ODE, the instantaneous turbulence fluctuation in the direction of wave advance, $u^{\prime}$, and the vertical $w^{\prime}$ are well related, especially in the middle of the water column (Ting and Kirby 1996); thus the ODEs play an important role in the generation of the Reynolds stress $\left\langle u^{\prime} w^{\prime}\right\rangle$ (the angle brackets represent time averaging). Because the eddies transport high-speed horizontal flow $\left(u^{\prime}>0\right)$ downward $\left(w^{\prime}<0\right),\left\langle u^{\prime} w^{\prime}\right\rangle$ is negative (Nadaoka et al. 1989; Ting and Kirby 1996; Cox and Kobayashi 2000; Melville et al. 2002). Near the bed, where most of the ODEs no longer exist, $\left\langle u^{\prime} w^{\prime}\right\rangle$ reduces to 0 . In the inner surf zone $\left\langle u^{\prime} w^{\prime}\right\rangle$ is smaller than near the initial breakpoint but is also more depth uniform (Stansby and Feng 2005; Kimmoun and Branger 2007). Ting (2001) argued that, if near-bed flow is dominated by bottomgenerated turbulence, $\left\langle u^{\prime} w^{\prime}\right\rangle$ should be positive: $\bar{u}$ and its vertical gradient are both negative, and positive $\left\langle u^{\prime} w^{\prime}\right\rangle$ is thus consistent with typical boundary layer flow. The change in sign of $\left\langle u^{\prime} w^{\prime}\right\rangle$ as the seabed is approached has not been observed in the aforementioned laboratory studies, however, and generally the intensity of bed-generated turbulence is assumed to be an order of magnitude smaller than the breaker-generated turbulence (Svendsen 1987). Beneath periodic plunging breakers, ODEs have also been observed beneath the initial breakpoint (e.g., Zhang and Sunamura 1990; Stansby and Feng 2005); farther onshore, vortices with a more two-dimensional horizontal structure develop where the splash-up that occurs immediately after plunging again hits the water surface (e.g., Zhang and Sunamura 1990; Kimmoun and Branger 2007). As for spilling waves, $\left\langle u^{\prime} w^{\prime}\right\rangle$ is negative, with maximum values at the first splash-up position (Stansby and Feng 2005; Kimmoun and Branger 2007). Collapsing breakers do not result in any coherent vortex motion (Zhang and Sunamura 1990).

In most laboratory studies with periodic waves, the turbulence fluctuations $u^{\prime}$ and $w^{\prime}$ were quantified by removing the ordered wave motion defined by an ensemble-averaging procedure (e.g., Svendsen 1987; Ting 2001). In natural wave fields, wave-turbulence decomposition is less straightforward. Frequency filtering (e.g., Newgard and Hay 2007) is not always appropriate as nearshore waves and turbulence often occupy the same frequency range. Gerbi et al. (2008) based their Reynolds stress estimates on cospectra of the total instantaneous cross-shore velocity $u$ and vertical velocity $w$ at frequencies below the wave band. Decomposition methods to separate the waves and turbulence across all of frequency space rely on velocity measurements at two adjacent single-point velocity sensors (e.g., Trowbridge 1998; Shaw and Trowbridge 2001; Feddersen and Williams 2007) or in two different bins of a velocity profiler (e.g., Whipple et al. 2006; Rosman et al. 2008); motions that are coherent between the two locations are identified as waves and, accordingly, the difference of the two velocity series contains only turbulence components. Nonetheless, Reynolds stress estimates are often contaminated by wave bias due to instrument tilt and a real wave stress associated with the orientation of the principal axes of the wave orbital motion. The often strong cross-shore wave orbital velocities and weak mean crossshore flows have so far precluded a detailed analysis of the temporal variation in and vertical structure of $\left\langle u^{\prime} w^{\prime}\right\rangle$ (Feddersen and Williams 2007): whether the laboratory $\left\langle u^{\prime} w^{\prime}\right\rangle$ findings are applicable to natural surf zone waves is not understood. Estimates of the alongshore Reynolds shear stress term, $\left\langle v^{\prime} w^{\prime}\right\rangle$, where $v^{\prime}$ is the alongshore instantaneous turbulence fluctuation, are less prone to wave bias because alongshore currents are often strong (0.1-1.5 m s$\left.{ }^{-1}\right)$, while the alongshore component of wave orbital flow is small because of wave refraction. Trowbridge and Elgar (2001) found the temporal variation in their $\left\langle v^{\prime} w^{\prime}\right\rangle$ estimates to correlate well with the near-bed quadratic drag $\left\langle v\left(v^{2}+u^{2}\right)^{0.5}\right\rangle(u$ and $v$ are the total instantaneous cross-shore and alongshore velocity, respectively), indicating that the observed nearbed $\left\langle v^{\prime} w^{\prime}\right\rangle$ was due to near-bed processes rather than surface-generated turbulence. In a wind-driven alongshore flow under nonbreaking waves in about 3-m depth, Feddersen and Williams (2007) found $\left\langle v^{\prime} w^{\prime}\right\rangle$ values that were about an order of magnitude smaller than those of Trowbridge and Elgar and were approximately depth uniform.

Here, measurements of instantaneous velocity below wave trough level in a natural surf zone are presented. The turbulence measurements were obtained with a vertical array of three acoustic Doppler velocimeters in the inner surf zone in water depths less than $3 \mathrm{~m}$ during high-energy wave conditions (the offshore significant wave height ranged between 2 and $8 \mathrm{~m}$ ) and with strong cross-shore and alongshore mean flows. The purpose in 


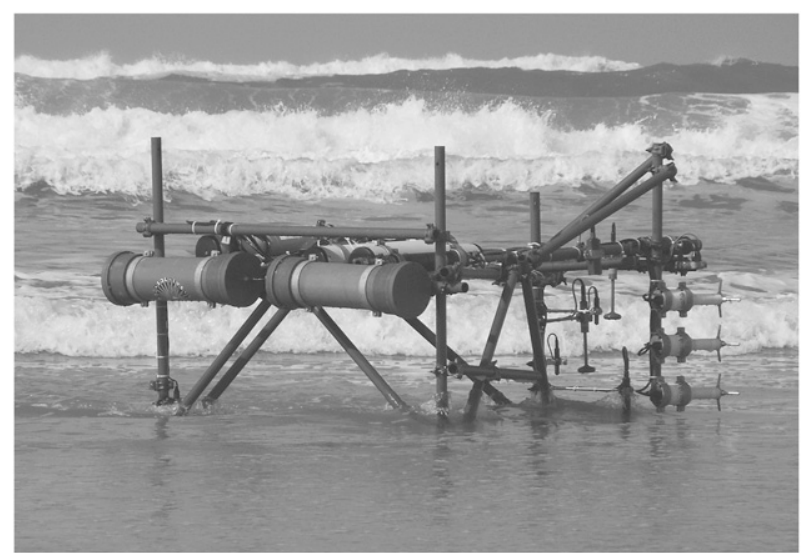

FIG. 1. Instrumented rig deployed at the neap low-tide water level during the ECORS Truc Vert 2008 experiment. The instruments were mounted on the northwestern side of the rig to ensure that the logging and power canisters did not influence the flow field at and the seabed below the sensors during conditions with waves from the west to northwest and with currents flowing southward (i.e., to the left in the image). The sensing volume of the upper of the three sideways-oriented ADVOs (the rightmost instruments in the image) is approximately $0.75 \mathrm{~m}$ above the seabed. The image was taken at low tide on 8 Mar 2008 (yearday 68).

this paper is to present the analysis of the vertical distribution of $\left\langle u^{\prime} w^{\prime}\right\rangle$ and $\left\langle v^{\prime} w^{\prime}\right\rangle$ with the overarching aim to determine whether surf zone turbulence is induced predominantly by breaking waves or is generated by processes at the seabed. Although the focus here is on the Reynolds stresses, we also explore the vertical distribution of the turbulent kinetic energy.

\section{Methods}

\section{a. Instruments}

The measurements were conducted at Truc Vert Beach (France), part of the approximately 100-km-long, northsouth oriented, uninterrupted coast between the Arcachon Lagoon tidal inlet to the south and the Gironde estuary to the north, in the framework of the ECORS Truc Vert 2008 field experiment. An instrumented rig (Fig. 1) was positioned at the neap low tide level to study the vertical structure of turbulence, oscillatory flow, crossshore and alongshore mean flow, and sediment concentration beneath breaking waves. Sensors used here include three single-point, sideways-oriented, $5-\mathrm{MHz}$ Sontek acoustic Doppler velocimeter ocean (ADVO) probes stacked in a $0.43-\mathrm{m}$-high vertical array to measure 3D mean and oscillatory flows and to estimate turbulence and stresses, and an acoustic backscatter sensor to estimate bed level. All three ADVOs were fitted with pressure, temperature, and pitch and roll sensors, as well as a compass, and had their own logger that sampled each instrument at $10 \mathrm{~Hz}$ in one burst of $24 \mathrm{~min}, 20 \mathrm{~s}$ each half hour. The vertical distance between the sample volumes of the lower (ADVO1) and middle (ADVO 2) sensor was $0.22 \mathrm{~m}$ and between $\mathrm{ADVO} 2$ and the upper (ADVO3) sensor $0.21 \mathrm{~m}$. The acoustic backscatter sensor (ABS), mounted about $0.45 \mathrm{~m}$ seaward of the ADVO array, comprised three transducers operating at 1.0, 2.0, and 4.0 MHz. For each transducer, the pulse repetition frequency was set to $80 \mathrm{~Hz}$, and the backscattered signals with 5 -mm vertical resolution were hardware averaged over 10 profiles to yield a 0.1 -s temporal resolution. The ABS was sampled during the same $24 \mathrm{~min}, 20 \mathrm{~s}$ as the ADVOs. Each half hour the three ADVOs and the ABS were triggered externally to ensure synchronous measurements. In the design and actual construction of the rig on the beach, special attention was paid to the positioning and orientation of all instruments to minimize disturbance of the flow field and of the seabed by the instruments themselves, by the rig and by its power and logging canisters. As the waves at Truc Vert Beach were expected to be predominantly incident from west to northwest and the alongshore currents to flow to the south, all instruments were mounted on the northwestern side of the rig with all power and logging canisters to the south (Fig. 1).

\section{b. Initial data processing}

The ADVO velocity series were quality controlled based on guidelines in Elgar et al. (2005) and Mori et al. (2007). Series with backscattered signal amplitudes less than 100 were considered to be not submerged throughout an entire burst and were culled from further processing. The despiking of the remaining series was carried out with a two-step velocity despiking procedure. First, beam velocities with correlations $<0.55$ were rejected and interpolated over following guidelines in Elgar et al. (2005). Then, beam velocities were transformed into the ADVO's orthogonal coordinate system, which was subsequently rotated into cross-shore $u$, alongshore $v$, and vertical $w$ velocity, with positive $u$ directed onshore, positive $v$ to the north, and positive $w$ upward (see the appendix). Finally, the $u, v$, and $w$ series were despiked with the phase-space method developed by Mori et al. (2007); again, detected spikes were interpolated over. The two-step despiking procedure was invoked because some spikes in the beam velocities did not necessarily coincide with low correlations. The total of number of rejected data points increased with sensor height above the bed and with wave energy conditions. At ADVO1 $50 \%$ and $99 \%$ of the bursts had less than $0.75 \%$ and $8.9 \%$ bad data; at ADVO3, these numbers were about $2 \%$ and $29 \%$. Note that the Elgar et al. quality-control guidelines 

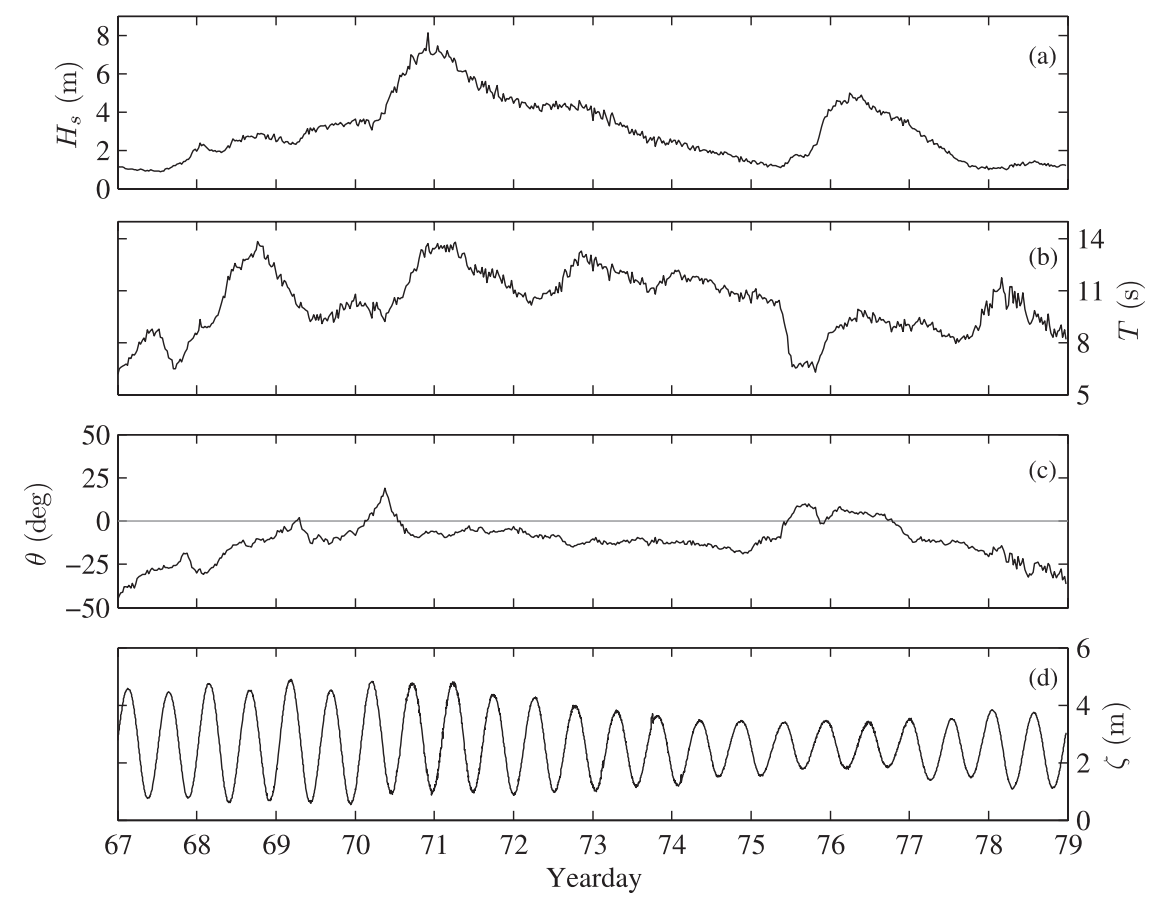

FIG. 2. Offshore spectral (a) significant wave height $H_{s}$, (b) wave period $T$, (c) energyweighted angle of incidence $\theta$ with respect to shore normal, and (d) water level $\zeta$ with respect to lowest astronomical tide vs time. The wave parameters in (a)-(c) were measured by a directional wave buoy located in about $20-\mathrm{m}$ depth, some $1.5 \mathrm{~km}$ from shore. Negative $\theta$ represent waves incident from the northwest. Water levels were measured by the pressure sensor of an offshore acoustic current Doppler profiler.

do not contain a rejection criterion based on the fraction of bad correlation points. The applied interpolation to fill bad data gaps will bias low turbulence fluctuations. Results in Feddersen (2010) indicate that the magnitude of this bias is likely to be minor for fractions of bad correlation points less than about $10 \%-15 \%$.

The elevation of the seabed at the rig with respect to chart datum $(\sim \mathrm{MSL})$ was estimated from the seabed echo in the ABS data using a thresholding algorithm. The time series of seabed elevation generally showed fluctuations on two distinct time scales. First, the seabed oscillated with amplitudes $\leqslant 0.2 \mathrm{~m}$ on a time scale of an hour or less. Second, the seabed increased or decreased slowly on a time scale of several hours. We assume that seabed undulations are due to the presence of smallscale migratory bed forms and the slow seabed changes to larger-scale beach change. Instantaneous bed elevation series of the three transducers were highly similar. To separate the two types of fluctuations, the instantaneous bed level estimated from each transducer was low-pass filtered with a cutoff of $3 \mathrm{~h}$. The three lowpassed series were then averaged. The time average of this transducer-averaged series over each measurement block of $24 \mathrm{~min}, 20 \mathrm{~s}$ represents the burst-averaged bed level with respect to chart datum and was used to determine the height above the bed for each ADVO during each burst.

For each burst, the pressure series at ADVO1 was converted to sea surface elevation $\eta$ using linear wave theory. The power spectrum of $\eta, S_{\eta}(f)$, where $f$ is frequency, was then computed using 409.6-s-long, detrended, and Bartlett-windowed segments with $50 \%$ overlapping, resulting in 18 degrees of freedom (Priestley 1981). The mean of $\eta$ was added to the estimated height of ADVO1 above the bed to yield the water depth $h$ at the rig for each burst. The pressure series at ADVO2 and ADVO3 yielded virtually identical $S_{\eta}$ and $h$.

\section{c. Experimental conditions}

The rig was deployed from 7 March (yearday 67) until 30 March (yearday 90) 2008. Here we focus on an approximately 12-day period from yearday 67 to 78 with high-energy wave conditions during which all three ADVOs were operational. Observed offshore wave and water level conditions are summarized in Fig. 2. On yearday 71 , waves generated by extratropical storm Johanna peaked at a spectral significant wave height $H_{s}$ of $8.2 \mathrm{~m}$ (Fig. 2a) with a period of nearly $14 \mathrm{~s}$ (Fig. 2b). Waves generated locally by another extratropical storm on yearday 76 reached $H_{s}$ of about $5.0 \mathrm{~m}$ with a period 
near $9.5 \mathrm{~s}$. For most of the experiment, waves were incident from northwesterly directions (negative angle of incidence, Fig. 2c). The first storm coincided with spring tide (range $\sim 4 \mathrm{~m}$ ), and the second one with neap tide (range $\sim 2 \mathrm{~m}$, see Fig. $2 \mathrm{~d}$ ).

Figure 3 provides a summary of the wave and water level conditions at the rig. The sea swell $(0.04-1 \mathrm{~Hz}) H_{s}$ were generally saturated (i.e., did not depend on offshore $H_{s}$ ) and varied with the local water depth $h$ (cf. Figs. $3 \mathrm{a}$ and $3 \mathrm{~b}$ ). The ratio of local $H_{s}$ to $h$ varied between 0.31 and 0.67 but was mainly $0.50-0.55$. To determine whether the rig was located beneath nonbreaking waves or in the outer or inner surf, we examined 10-min timeexposure video images of the study site collected concurrently with the rig measurements (Almar et al. 2010). The most conspicuous elements in such images are white, high-intensity bands induced by the foam on the front face of breaking waves, with the magnitude of the intensity related to the degree (i.e., frequency of occurrence) of wave breaking (e.g., Van Enckevort and Ruessink 2001; Aarninkhof and Ruessink 2004). Based on visual observations in the field, images with the rig submerged below a high-intensity band were interpreted as conditions when (virtually) all waves were breaking and were labeled as "inner surf zone." Similarly, images with the rig located at the transition from a high-intensity to a low-intensity area representative of nonbreaking waves were considered to be situations with occasional wave breaking and accordingly were labeled as "outer surf zone." Finally, images with the rig below low intensity were denoted "nonbreaking waves." As shown in Fig. $4, H_{s} / h \approx 0.38$ marks the transition between nonbreaking and weakly breaking outer-surf-zone waves, and $H_{s} / h \approx 0.48$ the transition between outer-surf-zone waves and inner-surf-zone bores. Similar $H_{s} / h$ values for surf zone bores on a dissipative beach were reported in Wright et al. (1982). Waves were observed to break by both plunging and spilling. The infragravity $(0.004-0.04 \mathrm{~Hz}) H_{s}$ did not depend on the tide but varied with the offshore $H_{s}\left(r^{2}=0.77\right.$, coefficient of proportionality $m=0.17$ ) and attained a maximum value of $1.52 \mathrm{~m}$ on yearday 71 (Fig. 3a). The sea swell were mostly incident from shore normal (Fig. 3d). Estimates of swell angle of incidence based on ADVO 2 and ADVO3 were generally within $1^{\circ}$ or $2^{\circ}$ from those based on ADVO1, within compass accuracy (see appendix). The swell rms horizontal velocity $\sigma_{t}$ [i.e., $\left(\sigma_{u}^{2}+\sigma_{v}^{2}\right)^{1 / 2}$, where $\sigma_{u}$ and $\sigma_{v}$ are the cross-shore and alongshore rms velocity, respectively] depended on $h$ and attained a maximum value of $\sim 0.6 \mathrm{~m} \mathrm{~s}^{-1}$ (Fig. 3e). The infragravity $\sigma_{t}$ often exceeded the swell $\sigma_{t}$, especially during lower stages of the tide and during both storms. Maximum infragravity $\sigma_{t}$ was $0.80 \mathrm{~m} \mathrm{~s}^{-1}$ (Fig. 3e).
Root-mean-square values of the vertical swell velocity increased with height above the bed in a manner consistent with linear wave theory (not shown). Burst-averaged alongshore currents $\bar{v}$ were generally toward the south and, when the rig was inside the surf zone, maximum at high tide (Fig. 3f). Maximum $\bar{v}$ at ADVO1 was $-1.12 \mathrm{~m} \mathrm{~s}^{-1}$. Burst-averaged cross-shore currents $\bar{u}$ were offshore directed and, as $\bar{v}$, largest at high tide, with a maximum value of $-0.43 \mathrm{~m} \mathrm{~s}^{-1}$. When the rig was seaward of the surf zone, $\bar{v}$ and $\bar{u}$ were $\sim 0 \mathrm{~m} \mathrm{~s}^{-1}$ (e.g., around high tide on yearday 67 ). The mean vertical velocities $\bar{w}$ at all three ADVOs were generally weak $\left(|\bar{w}| \approx 0.06 \mathrm{~m} \mathrm{~s}^{-1}\right)$ with stronger downward velocities near the seabed and at higher stages of the tide (not shown). The accuracy of the tilt sensor internal to each ADVO is $\pm 1^{\circ}$ (possibly better, see the appendix), indicating that the observed $\bar{w}$ are generally too large to be induced by uncertainties in the ADVOs coordinate transformation and are therefore most likely real.

To examine the vertical shear in $\bar{v}$ and $\bar{u}$, empirical orthogonal function decompositions [e.g., Von Storch and Zwiers (1999), see also section 3a] were performed on the vertical structure of $\bar{v}$ and $\bar{u}$. The first EOF, which compactly reproduces the greatest amount of variance, explains $98.7 \%$ and $98.3 \%$ of the variance in $\bar{v}$ and $\bar{u}$, respectively, and is used to reconstruct $\bar{v}$ and $\bar{u}$. The shear in $\bar{v}$ between ADVOs 1 and 2 and between ADVOs 2 and 3 always had the same sign as $\bar{v}$, consistent with a typical boundary layer flow. Shear values were similar for both ADVO pairs and varied between -0.005 and $-0.05 \mathrm{~s}^{-1}$. The shear in $\bar{u}$ between ADVOs 1 and 2 equaled $\bar{u}$ in sign, but that between ADVOs 2 and 3 was of opposite sign, qualitatively consistent with the parabolic shape of the vertical structure of $\bar{u}$ observed in laboratory (Stive and Wind 1986) and natural (Garcez Faria et al. 2000; Reniers et al. 2004) surf zones. Shear values in $\bar{u}$ between ADVOs 1 and 2 were always less than $-0.01 \mathrm{~s}^{-1}$, but those between ADVOs 2 and 3 peaked at almost $+0.1 \mathrm{~s}^{-1}$ during the first storm.

On yearday 67 the rig was positioned on an intertidal shoal between two approximately 400-m spaced rip channels. The bed level at the rig remained approximately constant from yearday 67 to 72 and subsequently decreased by approximately $0.5 \mathrm{~m}$ until yearday 78 (Fig. 3g) because of the southward migration of the rips. The standard deviation of the perturbations of the instantaneous ABS bed-level estimates from the low-passed estimates fluctuated with the tide to reach maximum values of 0.05 to $0.1 \mathrm{~m}$ around high tide (Fig. 3h). This suggests (Gallagher et al. 2005) that small-scale bedform amplitudes were largest at high tide. The standard deviations were approximately time independent at $0.01-$ $0.02 \mathrm{~m}$ during several tides during and following the 

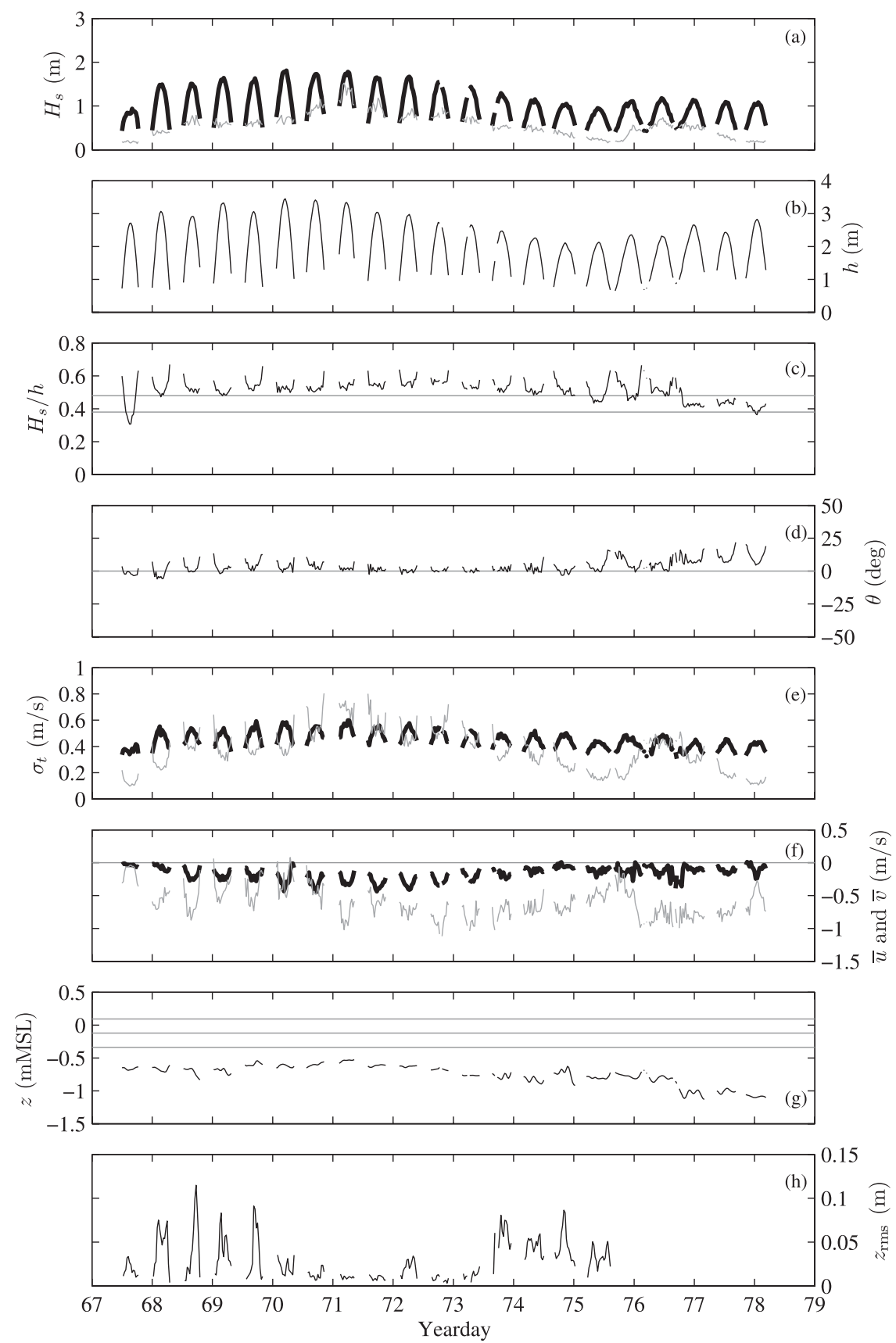

FIG. 3. Local spectral (a) significant wave height $H_{s}$ of the swell (thick line, 0.04-1 Hz) and infragravity (thin line, 0.004-0.04 Hz) band, (b) water depth $h$, (c) ratio of swell $H_{s}$ to $h$, (d) energy-weighted swell angle of incidence $\theta$ with respect to shore normal, (e) rms horizontal velocity $\sigma_{t}$ of the swell (thick line) and infragravity (thin line) band, (f) mean cross-shore $\bar{u}$ and alongshore $\bar{v}$ velocity, (g) bed elevation $z$ with respect to chart datum, and (h) standard deviation $z_{\text {rms }}$ of instantaneous bed level with respect to the low-passed bed level series vs time. In (c), the horizontal lines at $H_{s} / h=0.38$ and 0.48 represent the approximate boundaries between nonbreaking, weakly breaking, and fully breaking conditions. In (g), the three gray lines represent the elevations of the three ADVOs with respect to chart datum. Values in (a)-(f) are based on ADVO1. Seabed levels in (g) on yeardays 76-78 are based on the recordings of a 2D Sand Ripple Profiling Sensor, as the ABS had insufficient internal storage capacity to function during the entire period. 


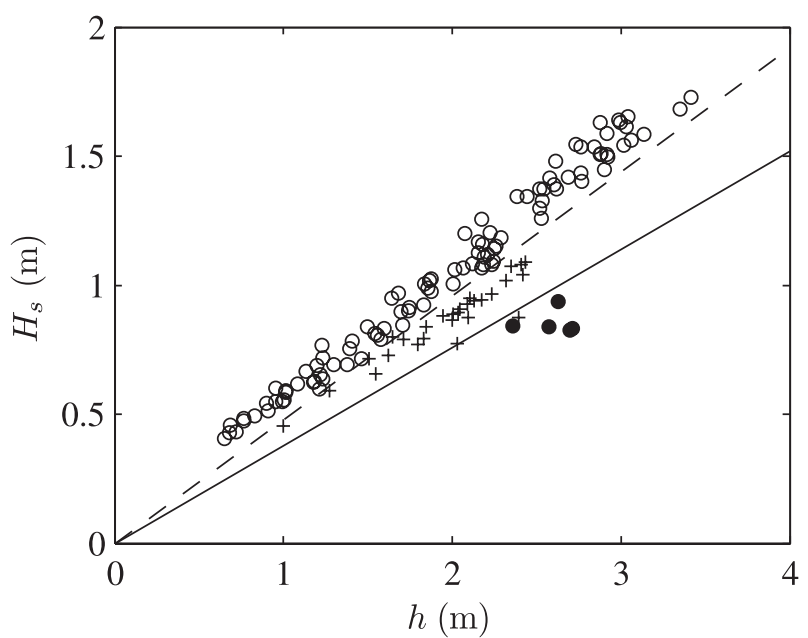

FIG. 4. Local spectral significant wave height $H_{s}$ of the swell (0.04-1 Hz) band vs water depth $h$, classified into inner surf zone (open circles), outer surf zone (pluses), and nonbreaking waves (filled circles) based on concurrent good quality 10-min time-exposure video images. The solid (dashed) line is $H_{s} / h=0.38(0.48)$.

main storm, suggesting that only then the seabed remained smooth (without bedforms) throughout. The median grain size at the rig was about $400 \mu \mathrm{m}$.

\section{d. Reynolds stress estimation method}

We used the two-sensor technique of Feddersen and Williams (2007) to estimate the turbulence fluctuations $u^{\prime}, v^{\prime}$, and $w^{\prime}$ and the shear stresses $\left\langle u^{\prime} w^{\prime}\right\rangle$ and $\left\langle v^{\prime} w^{\prime}\right\rangle$. The technique is a combination of the differencing approach of Trowbridge (1998) and the adaptive linearfiltering method of Shaw and Trowbridge (2001). The adaptive filtering removes, to a satisfactory degree, amplitude and phase differences between the wave velocities at the two sensors, causing the subsequent differencing to be more effective in removing the contribution of energetic gravity waves. The following focuses on $u^{\prime}, w^{\prime}$, and $\left\langle u^{\prime} w^{\prime}\right\rangle$ but is easily adaptable to $\left\langle v^{\prime} w^{\prime}\right\rangle$. We use subscripts of the form $A(B)$ to indicate that the turbulence and stress applies to the height of ADVO sensor A with adaptive-filtered velocities from ADVO B. Here, both $A$ and $B$ are either 1,2, or 3 .

In the technique of Feddersen and Williams (2007), $u_{A(B)}^{\prime}$ and $w_{A(B)}^{\prime}$ are estimated as the velocity-difference series $\Delta \widehat{U}_{A B}$ and $\Delta \widehat{W}_{A B}$, respectively, where $\Delta \widehat{U}_{A B}=$ $U_{A}-\widehat{U}_{A}$ with $U_{A}$ the demeaned cross-shore velocity at sensor $\mathrm{A}$ and $\widehat{U}_{A}$ the adaptive-filtered cross-shore velocity at sensor A, derived from $U_{B}$,

$$
\widehat{U}_{A}\left(t_{i}\right)=\sum_{j=-0.5(L-1)}^{j=0.5(L-1)} \mathbf{s}_{j} U_{B}\left(t_{i+j}\right) .
$$

Here $\mathbf{s}_{j}$ is a vector of weights of length $L$ that relate $U_{B}$ to $U_{A}$. The details of $\mathbf{s}_{j}$ are described in Shaw and Trowbridge (2001). In what follows, $L$ was set to $7 \mathrm{~s}$. Because the ADVOs measured at the same horizontal position, phase shifts were nil, and accordingly the results below were insensitive to the choice for $L ; \Delta \widehat{W}_{A B}$ is defined analogously, and $\left\langle u^{\prime} w^{\prime}\right\rangle_{A(B)}$ is the covariance of $\Delta \widehat{U}_{A B}$ and $\Delta \widehat{W}_{A B}$.

An example of measured cross-shore velocity and its decomposition into the wave and turbulence components is provided in Fig. 5. Figures 5a,b provide a 3-min block of demeaned cross-shore velocity at ADVO1 and ADVO2, $U_{1}$ and $U_{2}$, respectively. Also shown in Fig. $5 \mathrm{~b}$ is the adaptive-filtered cross-shore velocity at ADVO2 derived from the velocity series at $\mathrm{ADVO} 1, \widehat{U}_{2}$; it represents the wave component in $U_{2}$. The difference between $U_{2}$ and $\widehat{U}_{2}$ (Fig. 5c), $\Delta \widehat{U}_{21}$, is the estimated turbulence component in $U_{2}$ and is denoted $u_{2(1)}^{\prime}$. Figure $5 \mathrm{~d}$ illustrates the effects of the decomposition in frequency space for the selected burst. The $U_{2}$ power spectrum has a break in slope near $f=0.8 \mathrm{~Hz}$. In the $f=$ $1.5-3-\mathrm{Hz}$ range, the power spectral density is proportional to $f^{-1.5}$, close to the expected $f^{-5 / 3}$ dependence for the inertial subrange. For $f>4 \mathrm{~Hz}$, the spectrum flattens out, indicative of a noise floor, while for the $f=$ $0.2-0.4 \mathrm{~Hz}$ range the spectral densities fall off at a slope of -2.6 , close to the expected value of -3 for shallow water waves (e.g., Thornton 1977). The $\widehat{U}_{2}$ spectrum is virtually identical to that of $U_{2}$ for $f \leqslant 0.4 \mathrm{~Hz}$, implying that the motions at these frequencies are coherent between the two sensors and are dominated by waves. For higher frequencies the coherence decreases as the two spectra increasingly diverge. For $f>1 \mathrm{~Hz}$, the $\widehat{U}_{2}$ spectral density is about two to three orders of magnitude lower than that of $U_{2}$, implying that motions at these high frequencies are dominated by turbulence. Accordingly, the $u_{2(1)}^{\prime}$ spectral density equals that of $U_{2}$ for $f>1 \mathrm{~Hz}$. As can also be seen in Fig. $5 \mathrm{~d}$, the $u_{2(1)}^{\prime}$ spectral density increases in magnitude to well into the wind wave frequency band with a slope close to that observed for the $1.5-3-\mathrm{Hz}$ range.

Despite the adaptive filtering and the differencing, $\left\langle u^{\prime} w^{\prime}\right\rangle_{A(B)}$ and $\left\langle v^{\prime} w^{\prime}\right\rangle_{A(B)}$ can still contain considerable wave bias. Following Feddersen and Williams (2007), we used the cospectra of $\left\langle u^{\prime} w^{\prime}\right\rangle$ and $\left\langle v^{\prime} w^{\prime}\right\rangle$ to assess the quality of the Reynolds stress estimates and, hence, of $u^{\prime}, v^{\prime}$, and $w^{\prime}$ as well. The nondimensional integrated cospectrum (ogive) for $\left\langle u^{\prime} w^{\prime}\right\rangle$ is defined as

$$
\mathrm{Og}_{u^{\prime} w^{\prime}}(f)=\frac{\int^{f} \mathrm{Co}_{u^{\prime} w^{\prime}}(\widehat{f}) d \widehat{f}}{\left\langle u^{\prime} w^{\prime}\right\rangle},
$$

where $\mathrm{Co}_{u^{\prime} w^{\prime}}$ is the $u^{\prime} w^{\prime}$ cospectrum. The $v^{\prime} w^{\prime}$ ogive is defined similarly. When wave bias is minimal, the ogive 

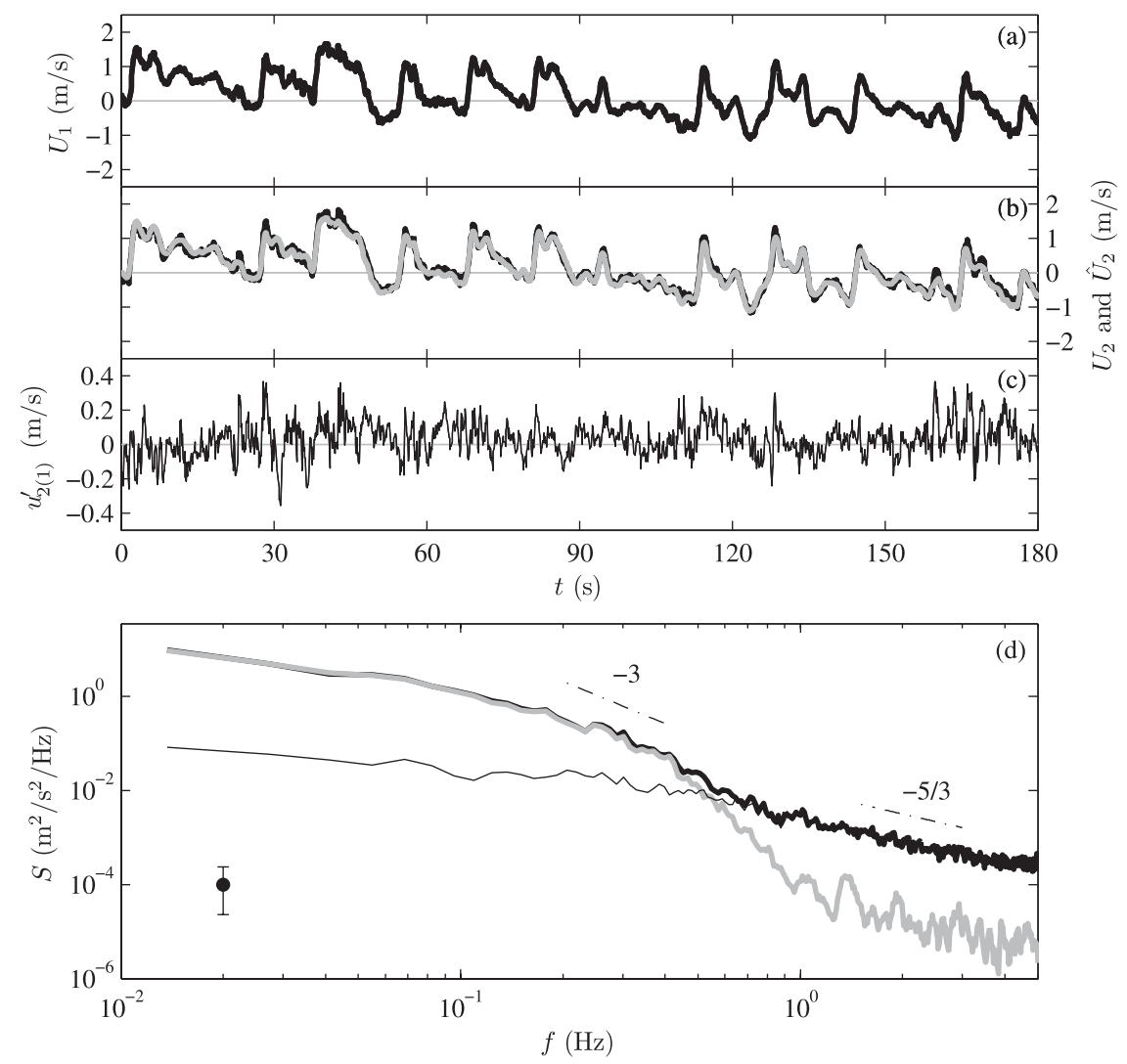

FIG. 5. Wave and turbulence decomposition for the cross-shore velocity measured in the burst starting at 1900 UTC 10 Mar 2008, with a 3-min block of (a) demeaned cross-shore velocity at ADVO1, $U_{1}$; (b) demeaned cross-shore velocity at ADVO2, $U_{2}$ (black line), and the adaptive-filtered cross-shore velocity at ADVO2 derived from the velocity series at ADVO1, $\widehat{U}_{2}$ (gray line); and (c) cross-shore turbulence velocity at ADVO2, $u_{2(1)}^{\prime}$. Note that these four series have a total length of $1460 \mathrm{~s}$ each. (d) Power spectral density $S$ of $U_{2}$ (thick black line), $\widehat{U}_{2}$ (thick gray line), and $u_{2(1)}^{\prime}$ (thin line) vs frequency $f$ for the selected burst. The spectra were computed by dividing each series in 73 -s-long, Hamming-windowed blocks with $50 \%$ overlap, yielding 98 degrees of freedom (Priestley 1981). The error bar indicates the $95 \%$ confidence level. Dashed-dotted lines indicate different spectral slopes (see text).

curves are expected to increase gently from 0 to 1 over a wide frequency range, similar to empirical curves determined in the wall region of the atmospheric boundary layer (Kaimal et al. 1972). In contrast, the curves increase sharply in a narrow frequency range or fluctuate wildly with frequency when the stress estimates are wave-bias contaminated. A robust test to reject bad Reynolds stress estimates with a fit to the empirical Kaimal et al. (1972) curves does not exist. Feddersen and Williams (2007) rejected Reynolds stress estimates when $\mathrm{Og}(f)$ was not always in the range $-0.5<\mathrm{Og}(f)<$ 1.6. Here, all $\operatorname{Og}(f)$ curves were compared visually to the empirical Kaimal et al. form and those that showed signs of wave bias were manually culled from further analysis. In hindsight, we found that most of the Reynolds stress estimates rejected during this admittedly subjective quality control would also have been detected if we had applied the Feddersen and Williams approach with a narrower $\operatorname{Og}(f)$ acceptance range: for example, $-0.3<\operatorname{Og}(f)<1.3$. In addition, all Reynolds stress estimates obtained for the tide during the peak of the first major storm were discarded as a visual check of the temporal evolution of the Reynolds stress estimates showed them to be remarkably at odds with the evolution during the other tides. Based on the work of Feddersen (2010), it is suspected that the large number of detected spikes (section $2 \mathrm{~b}$ ) may have made the velocity series unsuitable for turbulence studies. Finally, from the $\left\langle v^{\prime} w^{\prime}\right\rangle$ values passing the ogive test, those with $\bar{v}>0$ were rejected because of potential contamination with riggenerated turbulence.

The Feddersen and Williams method relies on sufficient vertical sensor separation that the turbulence components at the sensors are uncorrelated; however, at the 

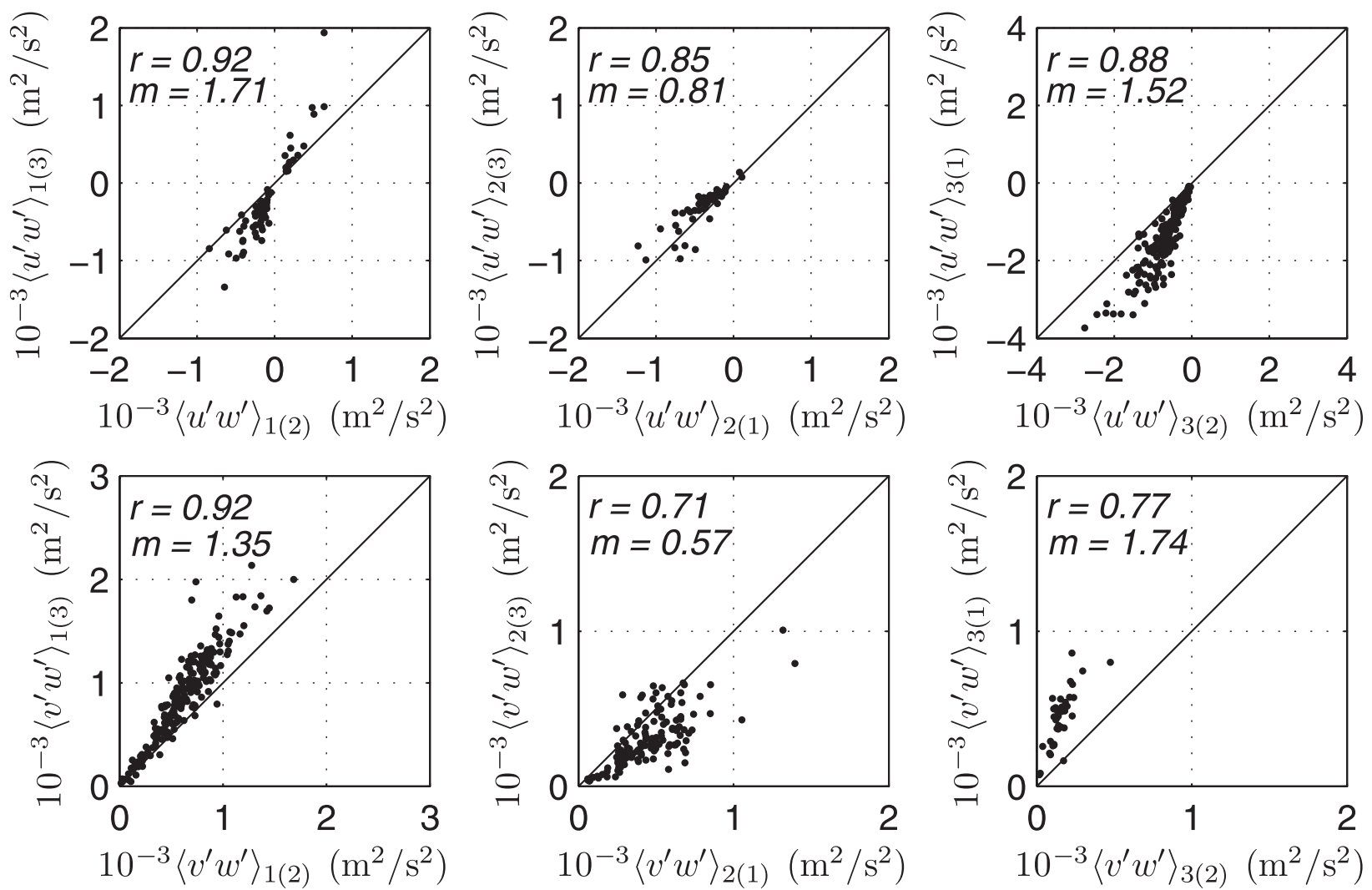

FIG. 6. Comparison of Reynolds stresses: (top) $\left\langle u^{\prime} w^{\prime}\right\rangle$ and (bottom) $\left\langle v^{\prime} w^{\prime}\right\rangle$. Diagonal lines are lines of equality. Correlation coefficient $r$ and slope of proportionality $m$ of best-fit linear lines are shown in the top left of each panel.

same time, the wave components must be perfectly coherent to avoid wave bias. If the separation distance is less than the dominant vertical turbulence length scale, turbulence components are correlated and will be eliminated by differencing, artificially reducing the Reynolds stress estimates. In the present work, the separation distance between adjacent ADVOs $(\sim 0.2 \mathrm{~m})$ is small relative to turbulence length scales beneath breaking waves $(\sim 0.1 h-0.3 h)$ reported in Pedersen et al. (1998) and Longo et al. (2002). Figure 6 and the associated linear regression statistics indicate a clear effect of turbulence correlation error as Reynolds stress estimates increase in magnitude with separation distance: the constant of proportionality $m$ of 1(3) versus 1(2) and of 3(1) versus 3(2) Reynolds stress estimates are all above 1. Reassuringly, the $95 \%$ confidence interval of the intercepts encompasses 0 (there is no bias), and the correlation coefficient exceeds 0.77 . Although it is obvious that the dominant vertical turbulence length scale is larger than about $0.2 \mathrm{~m}$, we do not know whether the distance of $0.41 \mathrm{~m}$ is sufficient to have no turbulence correlation error. Interestingly, the $m$ for 2(1) versus 2(3) Reynolds stress estimates is less than 1 , indicating a decrease in vertical turbulence length scale closer to the bed, consistent with laboratory experiments (Pedersen et al. 1998). To minimize the effect of turbulence correlation error on our work, the results in the following section are based on $A(B)=1(3), 2(1)$, and 3(1), resulting in 504 usable $\left\langle v^{\prime} w^{\prime}\right\rangle$ and 450 usable $\left\langle u^{\prime} w^{\prime}\right\rangle$ values. The vertical position of these estimates (Fig. 7) ranges from approximately $\xi / h \approx 0.08$ to 0.67 , where $\xi$ is the height above the seabed, with $3(20)\left\langle u^{\prime} w^{\prime}\right\rangle\left(\left\langle v^{\prime} w^{\prime}\right\rangle\right)$ estimates for $H_{s} / h<0.38,101$ (127) for $0.38 \leq H_{s} / h<0.48$, and 346 (357) for $H_{s} / h \geq 0.48$. Note that $\xi / h \approx 0.7$ corresponds to the wave trough level. The number of $\left\langle u^{\prime} w^{\prime}\right\rangle$ observations for nonbreaking waves is severely limited because these conditions did not occur often (Fig. 3c) and were affected most by wave bias.

\section{Results and discussion}

\section{a. Reynolds stresses}

Figures $8 \mathrm{a}-\mathrm{c}$ show $\left\langle u^{\prime} w^{\prime}\right\rangle_{1(3)},\left\langle u^{\prime} w^{\prime}\right\rangle_{2(1)}$, and $\left\langle u^{\prime} w^{\prime}\right\rangle_{3(1)}$ as a function of the relative wave height $H_{s} / h$. With an increase in $H_{s} / h$, we see increasingly larger, negative $\left\langle u^{\prime} w^{\prime}\right\rangle$, with stress values for the same $H_{s} / h$ increasing with height above the seabed (cf. Figs. $8 \mathrm{~b}$ and $8 \mathrm{c}$ ). The 


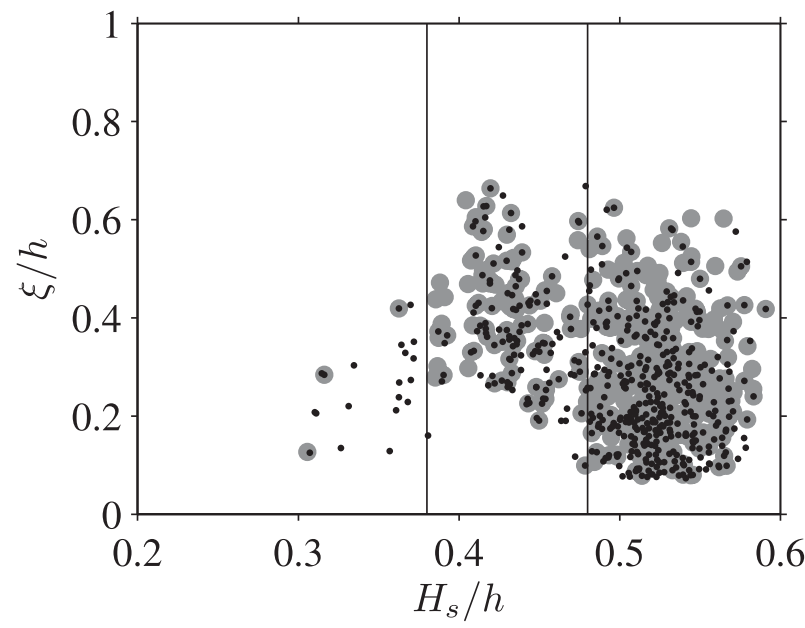

FIG. 7. Relative vertical position $\xi / h$, where $\xi$ is the elevation of the ADVO above the seabed, vs the relative wave height $H_{s} / h$ for $\left\langle u^{\prime} w^{\prime}\right\rangle$ (gray dots) and $\left\langle v^{\prime} w^{\prime}\right\rangle$ (black dots). The vertical lines at $H_{s} / h=0.38$ and 0.48 represent the approximate boundaries between nonbreaking, weakly breaking, and fully breaking conditions.

maximum $-\left\langle u^{\prime} w^{\prime}\right\rangle=-3.7 \times 10^{-3} \mathrm{~m}^{2} \mathrm{~s}^{-2}$ (Fig. 8c); Stansby and Feng (2005) and Kimmoun and Branger (2007) observed similar shear stress values under laboratory surf-zone bores. Intriguingly, $\left\langle u^{\prime} w^{\prime}\right\rangle_{1(3)}$ can also attain positive values for $H_{s} \geq 0.48$ (Fig. 8a). The appendix demonstrates that the $\left\langle u^{\prime} w^{\prime}\right\rangle$ values are robust to realistic variations in the rotation angles of the ADVOs.

To identify the vertical $\left\langle u^{\prime} w^{\prime}\right\rangle$ structure of simultaneous variation, the $\left\langle u^{\prime} w^{\prime}\right\rangle$ estimates were decomposed into three EOFs (e.g., Von Storch and Zwiers 1999),

$$
\left\langle u^{\prime} w^{\prime}\right\rangle(i, t)=\sum_{j=1}^{3} a_{j}(t) E_{j}(i) .
$$

Here $i$ refers to the ADVO level $(i=1,2,3), E_{j}$ are the (nondimensional) EOFs representing fixed vertical patterns $\left(\mathbf{E}^{\mathrm{T}} \mathbf{E}=\mathbf{I}\right.$, where $\mathbf{E}^{\mathrm{T}}$ is the transpose of $\mathbf{E}$ and $\mathbf{I}$ is the identity matrix), and $a_{j}$ are the (dimensional) temporal EOF coefficients. All EOF results below were based on Reynolds stress profiles containing at least two estimates that simultaneously passed the ogive test. In the first EOF decomposition, only negative $\left\langle u^{\prime} w^{\prime}\right\rangle$ were included, comprising 135 profiles. The first EOF of the negative $\left\langle u^{\prime} w^{\prime}\right\rangle$ decreases in the vertical (Fig. 9a) and contains $93 \%$ of the $\left\langle u^{\prime} w^{\prime}\right\rangle$ variance, indicating that the temporal variations in $\left\langle u^{\prime} w^{\prime}\right\rangle$ are highly coherent in the water column. The EOF coefficients depend, as expected from Figs. 8a-c, positively on the degree of wave breaking (Fig. 9b). The negative $\left\langle u^{\prime} w^{\prime}\right\rangle$ sign, its vertical structure, and the dependence of the EOF coefficients on $H_{s} / h$ all indicate that the dominant source of turbulence is due to wave breaking. The negative sign implies that (on average) high-speed cross-shore flow is transported downward, consistent with the presence of breaking-induced, downward propagating eddies as observed beneath laboratory breaking waves (Nadaoka et al. 1989; Ting and Kirby 1996; Cox and Kobayashi 2000; Melville et al. 2002). The breakup of these eddies (e.g., Nadaoka et al. 1989) likely causes $u^{\prime}$ and $w^{\prime}$ to become less coherent with distance below the sea surface. This breakup is also suggested by the positive dependence of the correlation between $u^{\prime}$ and $w^{\prime}, r_{\left\langle u^{\prime} w^{\prime}\right\rangle}$, on $\left\langle u^{\prime} w^{\prime}\right\rangle$ (the correlation coefficient of the best-fit linear between $r_{\left\langle u^{\prime} w^{\prime}\right\rangle}$ and $\left\langle u^{\prime} w^{\prime}\right\rangle$ is 0.76 , significant at the $95 \%$ confidence level). Thus, the decrease in the first EOF toward the seabed is associated with a reduced coherence between $u^{\prime}$ and $w^{\prime}$. The EOF1-derived negative $\left\langle u^{\prime} w^{\prime}\right\rangle$ are provided in Fig. 9c and show that, in general, $-\left\langle u^{\prime} w^{\prime}\right\rangle_{3(1)}>-\left\langle u^{\prime} w^{\prime}\right\rangle_{2(1)}>-\left\langle u^{\prime} w^{\prime}\right\rangle_{1(3)}$ for the same $\xi / h$. An identical $\xi / h$ implies an increasingly smaller $h$ from ADVO level 3 to 1 or transferred in the cross-shore, an increasingly closer position with respect to the shoreline. Thus, Fig. 9c may reflect that $\left\langle u^{\prime} w^{\prime}\right\rangle$ at the same relative height above the bed decreases in the onshore direction under self-similar (i.e., constant $H_{s} / h$ ) bores, consistent with the laboratory observations in Stansby and Feng (2005) and Kimmoun and Branger (2007).

In the second EOF decomposition, all $\left\langle u^{\prime} w^{\prime}\right\rangle$ were included, raising the number of profiles by 26 . The first EOF now explains $69 \%$ of the total variance. The loading for ADVO1 has reduced to nearly 0, whereas the loadings for the other two ADVO levels have remained unchanged (Fig. 9a). Also, the EOF1 coefficients are virtually identical to those based on the negative $\left\langle u^{\prime} w^{\prime}\right\rangle$ alone. On the whole, this implies that, with the inclusion of the positive $\left\langle u^{\prime} w^{\prime}\right\rangle$, the temporal variation in $\left\langle u^{\prime} w^{\prime}\right\rangle_{1(3)}$ is no longer coherent with the other estimates and that the positive $\left\langle u^{\prime} w^{\prime}\right\rangle_{1(3)}$ are unlikely to be breaking induced. The temporal variation in $\left\langle u^{\prime} w^{\prime}\right\rangle_{1(3)}$ is contained in the second EOF (Fig. 9a), comprising $28 \%$ of the total variance. As shown in Fig. 9d, the positive $a_{2}(t)$ are restricted to the lower $10 \%-20 \%$ of the water column. This suggests (Ting 2001) that they are due to the vertical shear of the near-bed cross-shore flow: $\bar{u}$ and $d \bar{u} / d \xi$ are both negative, and the positive $\left\langle u^{\prime} w^{\prime}\right\rangle$ sign is thus consistent with typical boundary layer flow. It is not obvious from our data why for $\xi / h<0.2$ some $\left\langle u^{\prime} w^{\prime}\right\rangle$ are positive while others are negative. Most of the positive $\left\langle u^{\prime} w^{\prime}\right\rangle$ were observed when $\bar{u}$ was fairly large (e.g., $|\bar{u}|>0.2 \mathrm{~m} \mathrm{~s}^{-1}$ at ADVO1) and the seabed was flat (i.e., no small-scale bed forms), but positive $\left\langle u^{\prime} w^{\prime}\right\rangle$ also occurred when $\bar{u}$ was lower and the bed was rippled. 

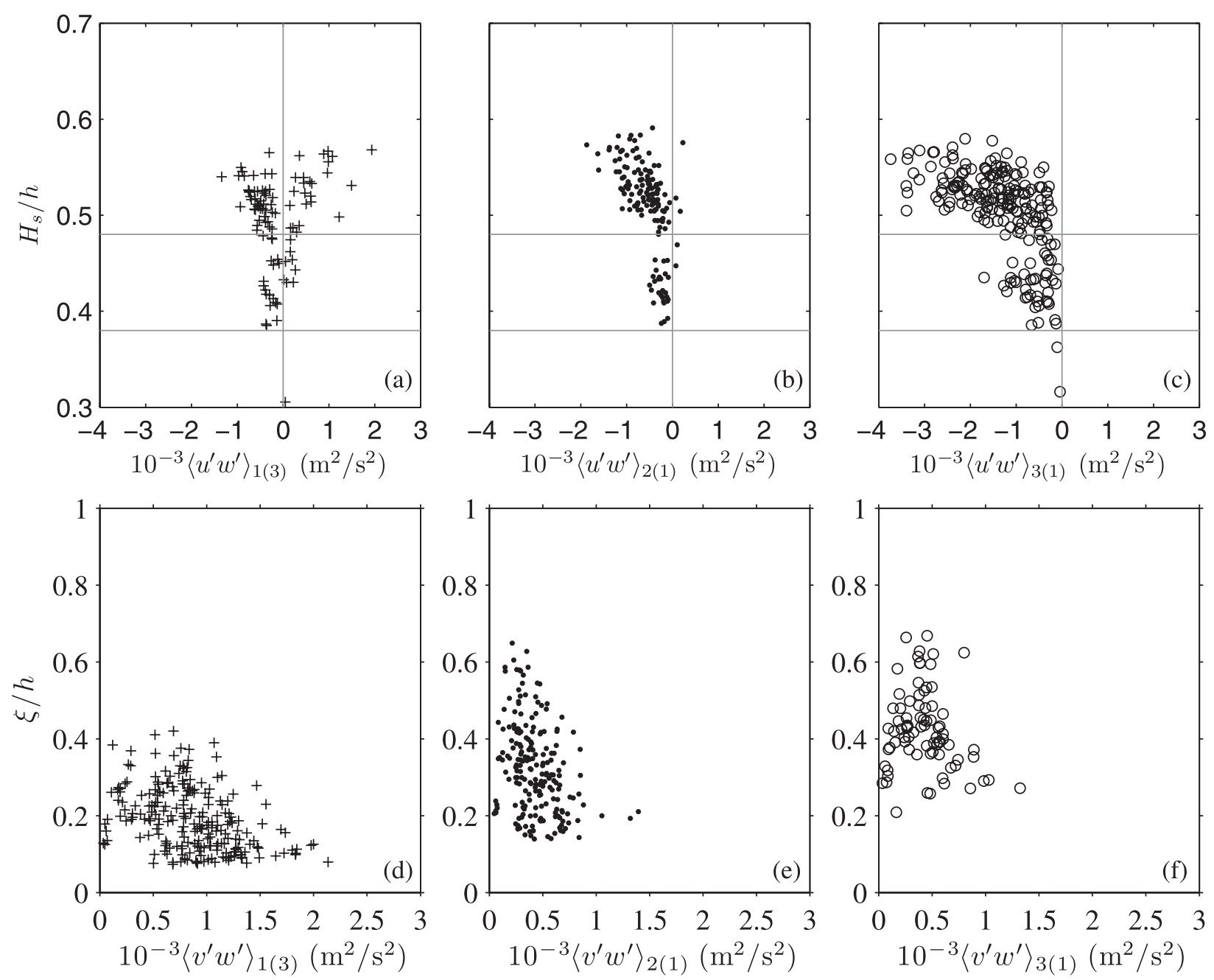

FIG. 8. Cross-shore Reynolds stress (a) $\left\langle u^{\prime} w^{\prime}\right\rangle_{1(3)}$, (b) $\left\langle u^{\prime} w^{\prime}\right\rangle_{2(1)}$, and (c) $\left\langle u^{\prime} w^{\prime}\right\rangle_{3(1)}$ vs relative wave height $H_{s} / h$. The two horizontal lines represent approximate boundaries between nonbreaking and weakly breaking waves $\left(H_{s} / h=0.38\right)$ and between weakly breaking waves and fully breaking, inner-surf-zone waves $\left(H_{s} / h=0.48\right)$. Alongshore Reynolds stress (d) $\left\langle v^{\prime} w^{\prime}\right\rangle_{1(3)}$, (e) $\left\langle v^{\prime} w^{\prime}\right\rangle_{2(1)}$, and (f) $\left\langle v^{\prime} w^{\prime}\right\rangle_{3(1)}$ vs the relative water depth $\xi / h$.

The estimated $\left\langle v^{\prime} w^{\prime}\right\rangle$ are all positive (Figs. 8d-f), that is, of opposite sign to the mean alongshore current. The maximum observed $\left\langle v^{\prime} w^{\prime}\right\rangle$ is $2.1 \times 10^{-3} \mathrm{~m}^{2} \mathrm{~s}^{-2}$, comparable to the estimates of Trowbridge and Elgar (2001) beneath breaking waves and strong currents in about 4.5-m depth (their $\xi / h$ was about 0.2 ) and about a factor of 10 larger than the approximately depth-uniform $\left\langle v^{\prime} w^{\prime}\right\rangle$ observed by Feddersen and Williams (2007) beneath nonbreaking waves and a weak, wind-driven alongshore current. The vertical structure of $\left\langle v^{\prime} w^{\prime}\right\rangle$, as represented by the first EOF (Fig. 10a), is remarkably different from that observed for $\left\langle u^{\prime} w^{\prime}\right\rangle$ (cf. Fig. 9a). The marked increase in EOF loading from ADVO level 2 to 1 (Fig. 10a) is consistent with expectations for boundary layer flows, in which the Reynolds stress is maximum at the (minute) height of the viscous wall region and then decreases gently to 0 at the top of the boundary layer $(\sim h)$ (Schlichting 1968; Pope 2008). The coefficients $a_{1}$ relate well to $\left\langle v\left(v^{2}+u^{2}\right)^{0.5}\right\rangle$ (Fig. 10b, $r=-0.75$ ), further confirming that $\left\langle v^{\prime} w^{\prime}\right\rangle$ is due to near-bed processes rather than surface-generated turbulence. In contrast to $\left\langle u^{\prime} w^{\prime}\right\rangle$, the EOF1-derived $\left\langle v^{\prime} w^{\prime}\right\rangle_{1(3)},\left\langle v^{\prime} w^{\prime}\right\rangle_{2(1)}$, and $\left\langle v^{\prime} w^{\prime}\right\rangle_{3(1)}$ overlap in $\xi / h$ space (Fig. 10c). The scatter in $\left\langle v w^{\prime}\right\rangle$ within relatively narrow $\xi / h$ bins is induced by variability in $\left\langle v\left(v^{2}+u^{2}\right)^{0.5}\right\rangle$. The constant of proportionality between $-\left\langle v^{\prime} w^{\prime}\right\rangle$ and $\left\langle v\left(v^{2}+u^{2}\right)^{0.5}\right\rangle$, often referred to as the drag coefficient $c_{d}$, equals $1.6 \times 10^{-3}$ (Fig. 10d, $r=0.75$ ) when based on observations within the $\xi / h=0.08$ to 0.12 range. Our $c_{d}$ is about a factor 2.5 higher than the Trowbridge and Elgar (2001) $c_{d}$ of $0.71 \times 10^{-3}$. Had we based our $c_{d}$ computation on observations in the $\xi / h=0.18$ to 0.22 range, we would have 

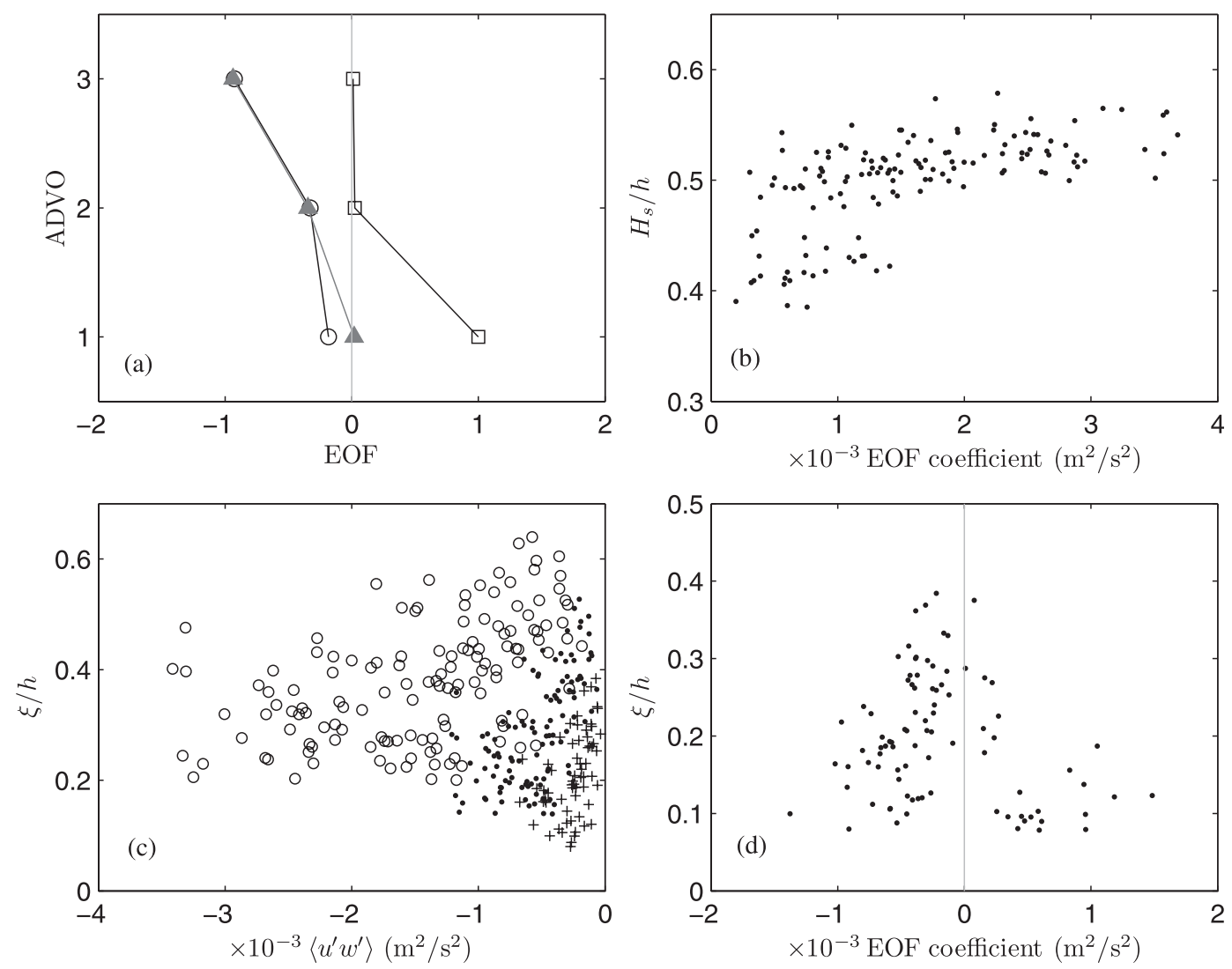

FIG. 9. EOF decomposition of $\left\langle u^{\prime} w^{\prime}\right\rangle$. (a) The vertical structure of the first EOF, $E_{1}(i)$, for all negative $\left\langle u^{\prime} w^{\prime}\right\rangle$ (open circles) and of $E_{1}(i)$ (triangles) and $E_{2}(i)$ (squares) for all $\left\langle u^{\prime} w^{\prime}\right\rangle$. (b) Temporal coefficients of the first EOF, $a_{1}(t)$, for all negative $\left\langle u^{\prime} w^{\prime}\right\rangle$ vs the relative wave height $H_{s} / h$. (c) EOF1 derived negative $\left\langle u^{\prime} w^{\prime}\right\rangle_{3(1)}$ (open circles), $\left\langle u^{\prime} w^{\prime}\right\rangle_{2(1)}$ (filled circles), and $\left\langle u^{\prime} w^{\prime}\right\rangle_{1(3)}$ (pluses). (d) Vertical distribution of the temporal coefficients of the second EOF, $a_{2}(t)$, for all $\left\langle u^{\prime} w^{\prime}\right\rangle$.

obtained $c_{d}=1.2 \times 10^{-3}(r=0.85)$, implying that at least part of the difference is due to different instrument height above the bed.

So far we have examined the mean value of the Reynolds stresses averaged over the duration of 1460-slong bursts. A visual inspection of the $u^{\prime} w^{\prime}$ and $v^{\prime} w^{\prime}$ series indicated that, as in all other high-Reynoldsnumber geophysical flows, major contributions to the Reynolds stresses occur in short duration, intermittent events whose maximum value can be more than 100 times the burst-averaged value, with longer-duration periods with minor values in between. As a consequence, the probability density functions of both $u^{\prime} w^{\prime}$ and $v^{\prime} w^{\prime}$ are highly kurtosed (the kurtosis $K_{a}$ of a demeaned time series $a$ is defined as $\left\langle a^{4}\right\rangle /\left\langle a^{2}\right\rangle^{2}$ and equals 3 for a Gaussian-distributed series $a$ ), with kurtosis $K_{u^{\prime} w^{\prime}}$ and $K_{v^{\prime} w^{\prime}}$ both ranging between about 20 and 100 without any obvious dependence on $\xi / h$. Heathershaw (1979) related an intermittency factor $\gamma$ for stress to kurtosis by $\gamma=3 / K$, which can be interpreted as the fraction of time the intermittent large contributions occur. Thus, the $K=20$ to 100 suggests that only during $3 \%-15 \%$ of the time $u^{\prime} w^{\prime}$ and $v^{\prime} w^{\prime}$ contribute noteworthily to the net stress, comparable to earlier findings beneath monochromatic breaking waves in the laboratory (Cox and Kobayashi 2000; Cox and Anderson 2001). An event-byevent analysis of each $u^{\prime} w^{\prime}$ and $v^{\prime} w^{\prime}$ series, where following Gordon and Witting (1977) events were defined using a zero-crossing method, further showed that the duration of the events that contribute most to the net stress typically varies between 0.6 and $1.5 \mathrm{~s}$.

\section{b. Turbulent kinetic energy}

We now continue our turbulence investigations by exploring the temporal and vertical variability of the turbulent kinetic energy $\left\langle k^{\prime}\right\rangle$, where $k^{\prime}$ is the turbulent kinetic energy fluctuation. For the 254 bursts in which both $\left\langle u^{\prime} w^{\prime}\right\rangle$ and $\left\langle v^{\prime} w^{\prime}\right\rangle$ passed the ogive test at the same time, $\left\langle k^{\prime}\right\rangle$ was calculated as $\left\langle k^{\prime}\right\rangle=0.5\left(\left\langle u^{\prime 2}\right\rangle+\left\langle v^{\prime 2}\right\rangle+\left\langle w^{\prime 2}\right\rangle\right)$. 

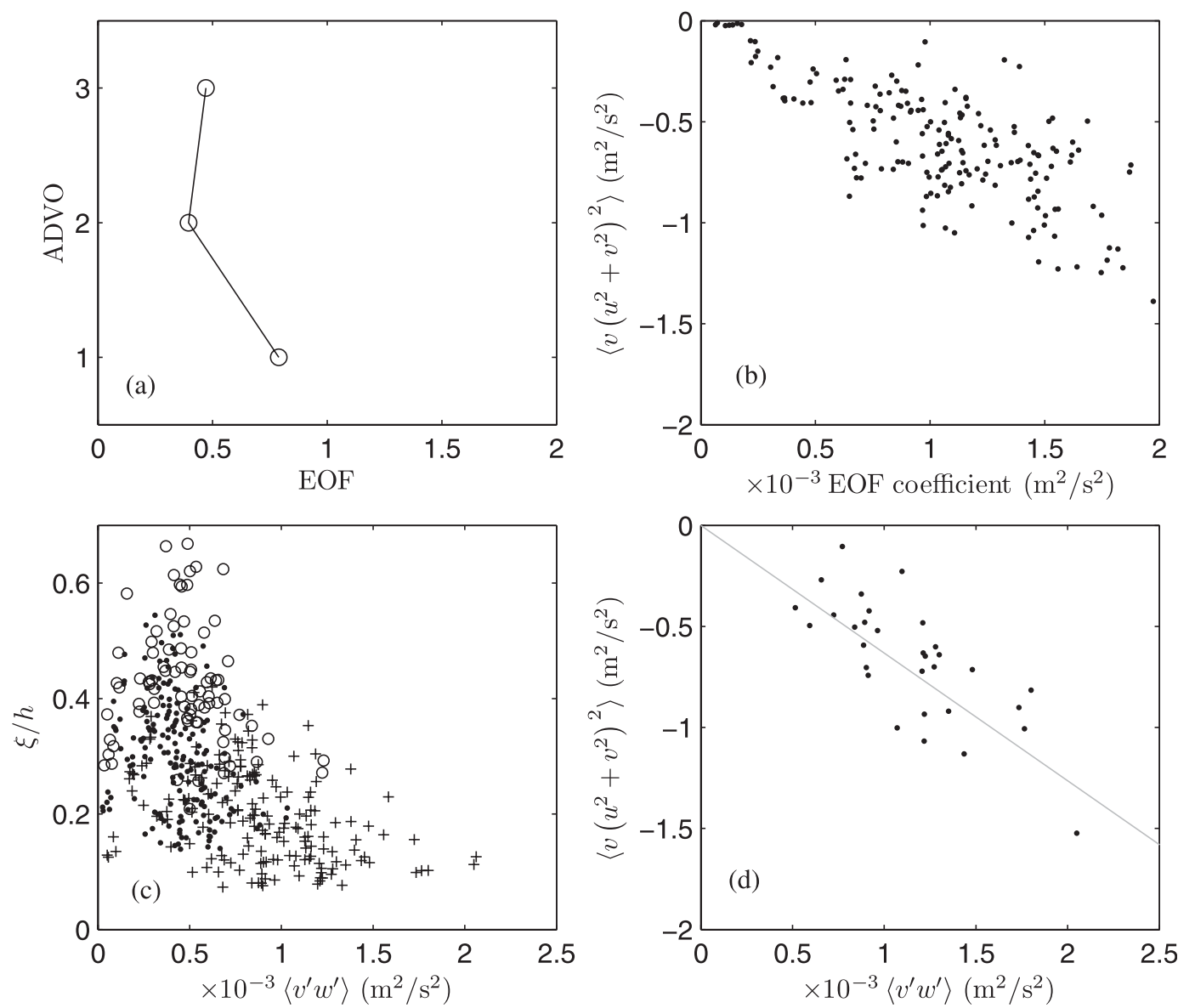

FIG. 10. EOF decomposition of $\left\langle v^{\prime} w^{\prime}\right\rangle$. (a) The vertical structure of the first EOF, $E_{1}(i)$. This EOF explains $88 \%$ of the total variance in $\left\langle v^{\prime} w^{\prime}\right\rangle$. (b) Temporal coefficients of the first EOF, $a_{1}(t)$, vs the near-bed quadratic $\operatorname{drag}\left\langle v\left(v^{2}+\right.\right.$ $\left.\left.u^{2}\right)^{0.5}\right\rangle$. (c) EOF1 derived $\left\langle v^{\prime} w^{\prime}\right\rangle_{3(1)}$ (open circles), $\left\langle v^{\prime} w^{\prime}\right\rangle_{2(1)}$ (filled circles), and $\left\langle v^{\prime} w^{\prime}\right\rangle_{1(3)}$ (pluses) vs $\xi / h$. (d) EOF1 derived $\left\langle v^{\prime} w^{\prime}\right\rangle_{1(3)}$ in the $\xi / h=0.08-0.12$ range vs $\left\langle v\left(v^{2}+u^{2}\right)^{0.5}\right\rangle$. The line is the best-fit linear line forced through the origin. Its slope results in $c_{d}=0.0016$.

The dominant mode of simultaneous variation in the 63 profiles with at least two $\left\langle k^{\prime}\right\rangle$ estimates is depth uniform (Fig. 11a), with the corresponding coefficients related positively to $H_{s} / h$ (Fig. 11b). The Froude-scaled turbulent kinetic energy $\left[\left\langle k^{\prime}\right\rangle /(g h)\right]^{1 / 2}$ (Svendsen 1987) beneath surf zone bores $\left(H_{s} / h \geq 0.48\right)$ varies between 0.015 and 0.04 , with a depth-averaged value of about 0.025 (Fig. 11c). The absence of a clear vertical trend in the (Froude scaled) turbulent kinetic energy indicates that vertical turbulence mixing is strong. Most laboratory observations of $\left[\left\langle k^{\prime}\right\rangle /(g h)\right]^{1 / 2}$ beneath surf zone bores after spilling (plunging) breaking are in the range from 0.03 to 0.07 (0.05 to 0.1; see Mocke 2001; Kimmoun and Branger 2007). The lower values observed here confirm laboratory findings in Ting $(2001,2002)$ and Scott et al. (2005) that turbulence intensities beneath irregular breaking waves are lower than those beneath regular waves with similar root-mean-square height and period at the offshore boundary. Our $\left[\left\langle k^{\prime}\right\rangle /(g h)\right]^{1 / 2}$ are, however, a factor of $\sim 2$ larger than those inferred by Mocke (2001) for the natural surf zone data of George et al. (1994). Mocke ascribed these low $\left[\left\langle k^{\prime}\right\rangle /(g h)\right]^{1 / 2}$ to inherent limitations of the frequency-filter approach applied by George et al. to separate turbulence from wave motions (see also Scott et al. 2005; Fig. 5d).

In most laboratory experiments the transversal component $\left\langle v^{\prime 2}\right\rangle$ was not measured, and the kinetic turbulence energy was estimated as $\left\langle k^{\prime}\right\rangle=1.33\left\langle k^{*}\right\rangle$, with $\left\langle k^{*}\right\rangle=0.5\left(\left\langle u^{\prime 2}\right\rangle+\left\langle w^{\prime 2}\right\rangle\right)$. The factor 1.33 stems from Svendsen (1987), who argued that the turbulence beneath breaking waves resembles that in a plane wake, $\left\langle u^{\prime 2}\right\rangle:\left\langle v^{\prime 2}\right\rangle:\left\langle w^{\prime 2}\right\rangle=0.43: 0.26: 0.32$ and, hence, $\left\langle k^{\prime}\right\rangle /\left\langle k^{*}\right\rangle=$ 1.33. In our data, the ratio of $\left\langle k^{\prime}\right\rangle$ to $\left\langle k^{*}\right\rangle$ is about 1.6 (Fig. 12a), implying that $\left\langle v^{\prime 2}\right\rangle$ is more important than in plane wake turbulence. Indeed, we find that for $\xi / h>0.2$, $\left\langle u^{\prime 2}\right\rangle:\left\langle v^{\prime 2}\right\rangle:\left\langle w^{\prime 2}\right\rangle \approx 0.41: 0.38: 0.21$ (Figs. 12b-d). Closer to 

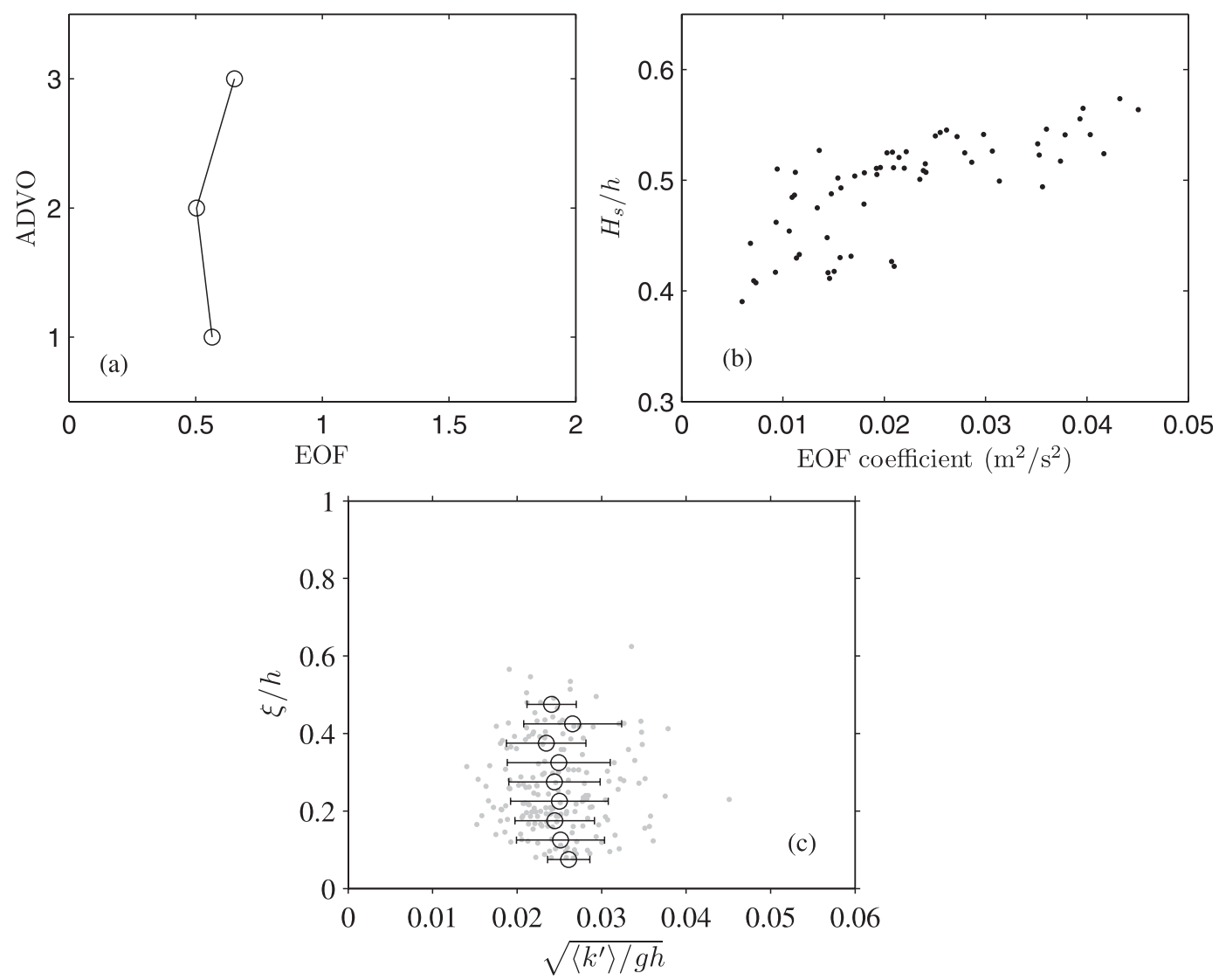

FIG. 11. (a) Vertical structure of the first EOF, $E_{1}(i)$, of $\left\langle k^{\prime}\right\rangle,(i, t)$. This EOF explains $84 \%$ of the total variance in $\left\langle k^{\prime}\right\rangle$. Note that the $x$ axis has the same range as in Fig. 10a. (b) Temporal coefficients of the first EOF, $a_{1}(t)$, vs the relative wave height $H_{s} / h$. (c) Vertical distribution of the Froude-scale turbulent kinetic energy $\left[\left\langle k^{\prime}\right\rangle /(g h)\right]^{1 / 2}$ for $H_{s} / h \geq 0.48$. Circles represent class-mean values according to $\xi / h \pm 0.025$; the horizontal bars are $\pm 1 \mathrm{std}$ dev. Circles and bars are shown only when the number of observations in a $\xi / h$ bin exceeded 5 .

the bed, $\left\langle u^{\prime 2}\right\rangle / 2\left\langle k^{\prime}\right\rangle$ increases to over 0.5 (Fig. 12b), while $\left\langle w^{\prime 2}\right\rangle / 2\left\langle k^{\prime}\right\rangle$ decreases to about 0.1 (Fig. 12d), causing an increase of the ratio of $\left\langle u^{\prime 2}\right\rangle /\left\langle w^{\prime 2}\right\rangle$ from $\sim 2$ to 5 . This increase is similar to that observed by Ting and Kirby (1996).

\section{Conclusions}

We have explored turbulence dynamics beneath natural surf zone waves by diagnosing the vertical structure of the Reynolds shear stresses $\left\langle u^{\prime} w^{\prime}\right\rangle$ and $\left\langle v^{\prime} w^{\prime}\right\rangle$. The negative sign of $\left\langle u^{\prime} w^{\prime}\right\rangle$ and its increase in magnitude away from the bed and with the degree of wave breaking all indicate that wave breaking is the dominant source of turbulence for the cross-shore shear stress. The negative $\left\langle u^{\prime} w^{\prime}\right\rangle$, corresponding to the downward transport of high-speed cross-shore flow, is consistent with laboratory observations beneath spilling and plunging breakers and points to the presence of breakinginduced vortices; the decrease in $\left\langle u^{\prime} w^{\prime}\right\rangle$ and in the correlation between $u^{\prime}$ and $w^{\prime}$ closer to the seabed suggests that these vortices disintegrate as they propagate downward. The alongshore shear stress is, in contrast, dominated by bed-generated turbulence and decreases with height above the bed, especially in the lower 30\%$40 \%$ of the water column. The drag coefficient amounts to $1.6 \times 10^{-3}$, a common near-shore value, but it is sensitive to instrument height. As in other high-Reynoldsnumber geophysical flows, time series of $\left\langle u^{\prime} w^{\prime}\right\rangle$ and $\left\langle v^{\prime} w^{\prime}\right\rangle$ comprise intermittently large, short-duration (here, $\sim 1 \mathrm{~s}$ ) stress events that in our data contribute considerably to the net stress from only $3 \%$ to $15 \%$ of the time. We further find that the turbulent kinetic energy is approximately depth uniform and increases with the degree of wave breaking. The depth-averaged value of the Froude-scaled turbulent kinetic energy amounts to 0.025 . This is less than observed beneath laboratory bores and thus confirms earlier results that turbulence intensities beneath random waves are less than beneath periodic waves. 

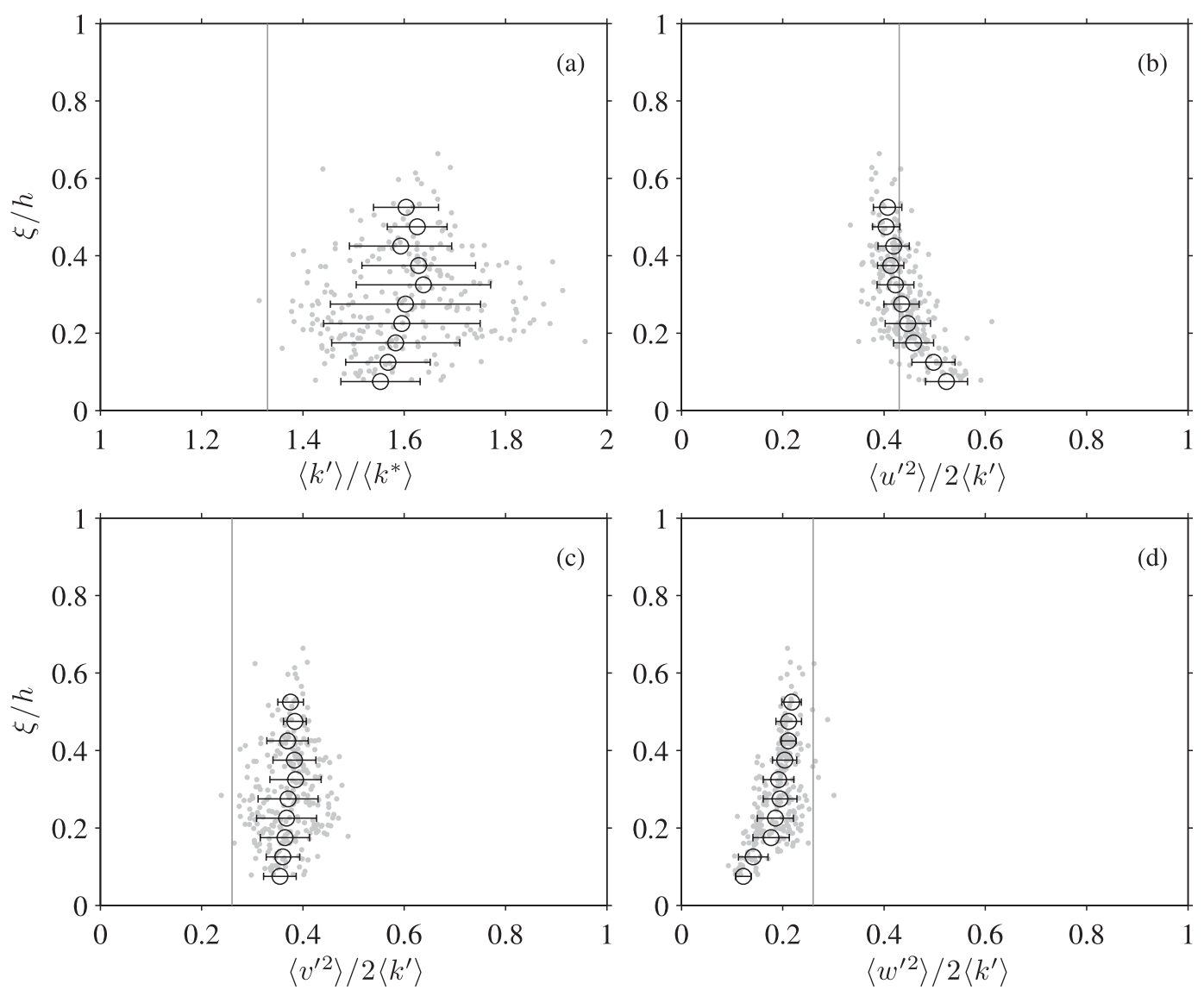

FIG. 12. Vertical distribution (a) $\left\langle k^{\prime}\right\rangle /\left\langle k^{*}\right\rangle$, (b) $\left\langle u^{\prime 2}\right\rangle / 2\left\langle k^{\prime}\right\rangle$, (c) $\left\langle v^{\prime 2}\right\rangle / 2\left\langle k^{\prime}\right\rangle$, and (d) $\left\langle w^{\prime 2}\right\rangle / 2\left\langle k^{\prime}\right\rangle$. Circles represent class-mean values according to $\xi / h \pm 0.025$; the horizontal bars are \pm 1 std dev. Circles and bars are shown only when the number of observations in a $\xi / h$ bin exceeded 5 . The gray vertical lines indicate values expected from plane wake turbulence (Svendsen 1987).

Acknowledgments. The field data were collected within the structure of the multi-institutional ECORS (SHOM-DGA) project. Nadia Sénéchal, Fabrice Ardhuin, and the members of the Bordeaux team are acknowledged for providing excellent logistic support. I am greatly indebted to Marcel van Maarseveen, Henk Markies, and Bas van Dam for their electronic and mechanic design of the rig and their support in the field. In addition, Falk Feddersen, R. T. Guza, Maarten van der Vegt, and the two anonymous reviewers provided useful feedback on this work. This was funded by the Netherlands Organisation for Scientific Research NWO under Personal Award 864.04.007.

\section{APPENDIX}

\section{Rotation}

The rotation of the ADVO Cartesian $x-y-z$ coordinate scheme into the $u-v-w$ scheme deployed here is a three-dimensional rotation, with the rotation angle in the $x y$ (horizontal) plane known as heading, in the $x z$ plane as pitch, and in the $y z$ plane as roll. The pitch and roll used for each burst were the median values of the instantaneous $(10 \mathrm{~Hz})$ pitch and roll series sampled by the ADVO internal tilt sensor. The median pitch and roll during the 12-day period analyzed here were always within $1.6^{\circ}$ from 0 and did not vary by more than $0.4^{\circ}$. Changes exceeding the tilt sensor's $0.1^{\circ}$ resolution coincided at the three ADVOs and were limited to single events on yeardays 68 and 76 for the pitch and roll, respectively. The ADVO internal compass reading was not used because of the nearby scaffolding and power canisters. Instead, the orientation of each ADVO acoustic transmitter was determined with an external compass at the onset and the end of the 12-day period. The identical headings and the minimal pitch and roll variation imply that the instrument rig rotated neither horizontally nor vertically, despite the strong cross-shore wave forces and the sediment erosion after yearday 71 . According to the 

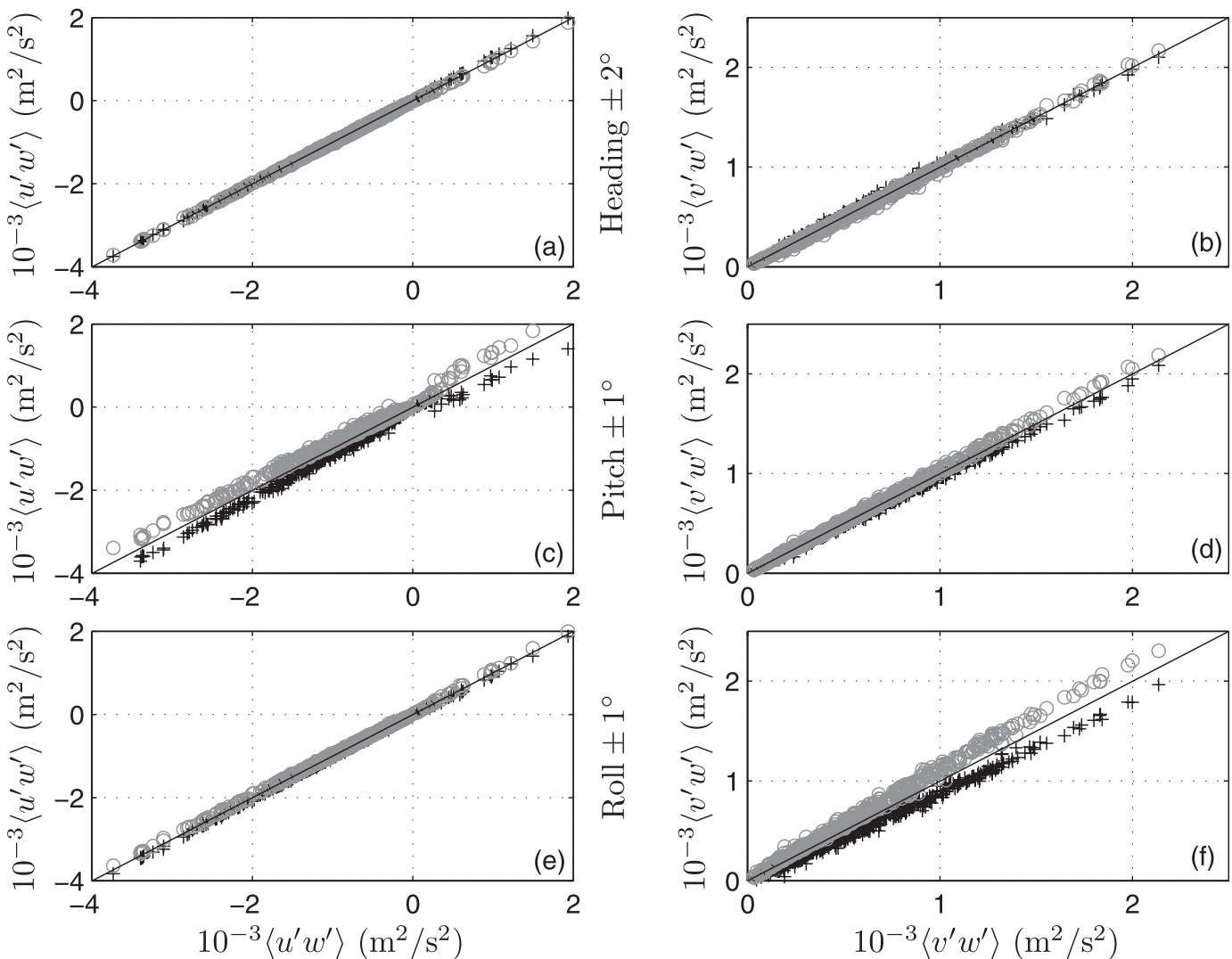

FIG. A1. Sensitivity of Reynolds stresses (a),(c),(e) $\left\langle u^{\prime} w^{\prime}\right\rangle$ and (b),(d),(f) $\left\langle v^{\prime} w^{\prime}\right\rangle$ to uncertainty in the angles to rotate the velocities from the ADVO's Cartesian $x-y-z$ into the $u-v-w$ coordinate schemethe: pluses (gray circles) correspond to an increase (decrease) in one of the rotation angles.

manufacturer (PNI Corporation), the pitch and roll accuracy is $\pm 0.2^{\circ}$ but is specified as $\pm 1^{\circ}$ in SonTek (2001). We estimate the heading accuracy to be $\pm 2^{\circ}$ at most.

Here we examine the sensitivity of $\left\langle u^{\prime} w^{\prime}\right\rangle$ and $\left\langle v^{\prime} w^{\prime}\right\rangle$ to realistic, upper limits in the uncertainties in the three rotation angles. In each sensitivity test, one of three rotation angles was changed and the applied change was identical for both ADVO sensors. As demonstrated in Figs. A1a,b, neither $\left\langle u^{\prime} w^{\prime}\right\rangle$ nor $\left\langle v^{\prime} w^{\prime}\right\rangle$ are sensitive to $\pm 2^{\circ}$ variations in heading (Figs. A1a,b). As expected, a change in the pitch affects $\left\langle u^{\prime} w^{\prime}\right\rangle$ more than $\left\langle v^{\prime} w^{\prime}\right\rangle$ (Figs. A1c-d), with a pitch change of $\pm 1^{\circ}$ increasing (decreasing) negative (positive) $\left\langle u^{\prime} w^{\prime}\right\rangle$; a change of $-1^{\circ}$ has the opposite effect. Interestingly, the sensitivity of $\left\langle u^{\prime} w^{\prime}\right\rangle$ to the pitch increases with proximity to the seabed. This is, for instance, obvious from Fig. A1c since the positive $\left\langle u^{\prime} w^{\prime}\right\rangle(\xi / h<0.15-0.2)$ are affected more than the negative $\left\langle u^{\prime} w^{\prime}\right\rangle$ with a similar magnitude (observed higher up in the vertical). A $\pm 1^{\circ}$ change in roll modifies $\left\langle v^{\prime} w^{\prime}\right\rangle$ by approximately $\pm 10 \%$ (Fig. A1f) and changes the $c_{d}$ estimate by the same amount; $\left\langle u^{\prime} w^{\prime}\right\rangle$ remains virtually unaltered (Fig. A1e) for the $\pm 1^{\circ}$ roll uncertainty. On the whole, Fig. A1 implies that our interpretation of the vertical structure of $\left\langle u^{\prime} w^{\prime}\right\rangle$ and $\left\langle v^{\prime} w^{\prime}\right\rangle$ (Fig. 8) is robust to realistic uncertainty in the three rotation angles.

\section{REFERENCES}

Aagaard, T., and M. G. Hughes, 2010: Breaker turbulence and sediment suspension in the surf zone. Mar. Geol., 271, 250-259.

Aarninkhof, S. G. J., and B. G. Ruessink, 2004: Video observations and model predictions of depth-induced wave dissipation. IEEE Trans. Geosci. Remote Sens., 42, 2612-2622.

Almar, R., B. Castelle, B. G. Ruessink, N. Sénéchal, P. Bonneton, and V. Marieu, 2010: Two- and three-dimensional doublesandbar system behaviour under intense wave forcing and meso-macro tidal range. Cont. Shelf Res., 30, 781-792.

Cox, D. T., and N. Kobayashi, 2000: Identification of intense, intermittent coherent motions under shoaling and breaking waves. J. Geophys. Res., 105, 14 223-14 236. , and S. L. Anderson, 2001: Statistics of intermittent surf zone turbulence and observations of large eddies using PIV. Coastal Eng. J., 43, 121-131.

Elgar, S., B. Raubenheimer, and R. T. Guza, 2005: Quality control of acoustic Doppler velocimeter data in the surfzone. Meas. Sci. Technol., 16, 1889-1893.

Feddersen, F., 2010: Quality controlling surf zone acoustic Doppler velocimeter observations to estimate the turbulent dissipation rate. J. Atmos. Oceanic Technol., 12, 2039-2055. 
— and J. H. Trowbridge, 2005: The effect of wave breaking on surf zone turbulence and alongshore currents: A modeling study. J. Phys. Oceanogr., 35, 2187-2203.

— nolds stress vertical structure in the nearshore. J. Atmos. Oceanic Technol., 24, 102-116.

Gallagher, E. L., S. Elgar, R. T. Guza, and E. B. Thornton, 2005: Estimating nearshore bedform amplitudes with altimeters. Mar. Geol., 216, 51-57.

Garcez Faria, A. F., E. B. Thornton, T. C. Lippmann, and T. P. Stanton, 2000: Undertow over a barred beach. J. Geophys. Res., 105, 16 999-17 010.

George, R., R. E. Flick, and R. T. Guza, 1994: Observations of turbulence in the surf zone. J. Geophys. Res., 99, 801-810.

Gerbi, G. P., J. H. Trowbridge, J. B. Edson, A. J. Plueddemann, E. A. Terray, and J. J. Fredericks, 2008: Measurements of momentum and heat transfer across the air-sea interface. J. Phys. Oceanogr., 38, 1054-1072.

Gordon, C. M., and J. Witting, 1977: Turbulent structure in a benthic boundary layer. Bottom Turbulence, J. C. J. Nihoul, Ed., Oceanography Series, Vol. 19, Elsevier, 59-81.

Heathershaw, A. D., 1979: The turbulent structure of the bottom boundary layer in a tidal current. Geophys. J. Roy. Astron. Soc., 58, 395-430.

Kaimal, J. C., J. C. Wyngaard, Y. Izumi, and O. R. Cote, 1972: Spectral characteristics of surface-layer turbulence. Quart. J. Roy. Meteor. Soc., 98, 563-589.

Kimmoun, O., and H. Branger, 2007: A particle image velocimetry investigation on laboratory surf-zone breaking waves over a sloping beach. J. Fluid Mech., 588, 353-397.

Longo, S., M. Petti, and I. J. Losada, 2002: Turbulence in the swash and surf zones: A review. Coastal Eng., 45, 129-147.

Melville, W. K., F. Veron, and C. J. White, 2002: The velocity field under breaking waves: Coherent structures and turbulence. J. Fluid Mech., 454, 203-233.

Mocke, G. P., 2001: Structure and modeling of surf zone turbulence due to wave breaking. J. Geophys. Res., 106, 17 039-17 057.

Mori, N., T. Suzuki, and S. Kakuno, 2007: Noise of acoustic Doppler velocimeter data in bubbly flows. J. Eng. Mech., 133, 122-125.

Nadaoka, K., S. Ueno, and T. Igarashi, 1988: Sediment suspension due to large scale eddies in the surf zone. Proc. 21st Int. Conf. on Coastal Engineering, New York, NY, American Society of Civil Engineering, 1646-1660.

— M. Hino, and Y. Koyano, 1989: Structure of the turbulent flow field under breaking waves in the surf zone. J. Fluid Mech., 204, 359-387.

Newgard, J. P., and A. E. Hay, 2007: Turbulence intensity in the wave boundary layer and bottom friction under (mainly) flat bed conditions. J. Geophys. Res., 112, C09024, doi:10.1029/ 2006JC003881.

Okayasu, A., H. Katayama, H. Tsuruga, and H. Iwasawa, 2002: A laboratory experiment on velocity field near bottom due to obliquely descending eddies. Proc. 28th Int. Conf. on Coastal Engineering, New York, NY, American Society of Civil Engineering, 521-531.

Pedersen, C., R. Deigaard, and J. Sutherland, 1998: Measurements of the vertical correlation in turbulence under broken waves. Coastal Eng., 35, 231-249.

Pope, S. B., 2008: Turbulent Flows. 5th ed. Cambridge University Press, $771 \mathrm{pp}$.

Priestley, M. B., 1981: Spectral Analysis and Time Series. Probability and Mathematical Statistics Series, Academic Press, $890 \mathrm{pp}$.
Reniers, A. J. H. M., E. B. Thornton, T. P. Stanton, and J. A. Roelvink, 2004: Vertical flow structure during Sandy Duck: Observations and modeling. Coastal Eng., 51, $237-$ 260, doi:10.1016/j.coastaleng.2004.02.001.

Rosman, J. H., J. L. Hench, J. R. Koseff, and S. T. Monismith, 2008: Extracting Reynolds stresses from acoustic Doppler current profiler measurements in wave-dominated environments. J. Atmos. Oceanic Technol., 25, 286-306.

Schlichting, H., 1968: Boundary-Layer Theory. 6th ed. Series in Mechanical Engineering, McGraw-Hill, 747 pp.

Scott, C. P., D. T. Cox, T. B. Maddux, and J. W. Long, 2005: Largescale laboratory observations of turbulence on a fixed barred beach. Meas. Sci. Technol., 16, 1903-1912.

Shaw, W. J., and J. H. Trowbridge, 2001: The direct estimation of near-bottom turbulent fluxes in the presence of energetic wave motions. J. Atmos. Oceanic Technol., 18, 1540-1557.

SonTek, 2001: SonTek/YSI ADVField/Hydra: Operation manual. SonTek/YSI Manual, 113 pp.

Stansby, P. K., and T. Feng, 2005: Kinematics and depth-integrated terms in surf zone waves from laboratory measurements. J. Fluid Mech., 529, 279-310.

Stive, M. J. F., and H. G. Wind, 1986: Cross-shore mean flow in the surf zone. Coastal Eng., 10, 325-340.

Svendsen, I. A., 1987: Analysis of surf zone turbulence. J. Geophys. Res., 92, 5115-5124.

Terray, E. A., M. A. Donelan, Y. C. Agrawal, W. M. Drennan, K. K. Kahma, A. J. Willians, and P. Hwang, 1996: Estimates of kinetic energy dissipation under breaking waves. J. Phys. Oceanogr., 26, 792-807.

Thornton, E. B., 1977: Rederivation of the saturation range in the frequency spectrum of wind-generated gravity waves. J. Phys. Oceanogr., 7, 137-140.

Ting, F. C. K., 2001: Laboratory study of wave and turbulence velocities in a broad-banded irregular wave surf zone. Coastal Eng., 43, 183-208.

_ 2002: Laboratory study of wave and turbulence characteristics in narrow-band irregular breaking waves. Coastal Eng., 46, 291-313.

— , and J. T. Kirby, 1995: Dynamics of surf-zone turbulence in a strong plunging breaker. Coastal Eng., 24, 177-204.

_ breaker. Coastal Eng., 27, 131-160.

Trowbridge, J. H., 1998: On a technique for measurement of turbulent shear stress in the presence of surface waves. J. Atmos. Oceanic Technol., 15, 290-298.

— zone. J. Phys. Oceanogr., 31, 2403-2417.

Van Enckevort, I. M. J., and B. G. Ruessink, 2001: Effects of hydrodynamics and bathymetry on video estimates of nearshore sandbar position. J. Geophys. Res., 106, 16 969-16979.

Von Storch, H., and F. W. Zwiers, 1999: Statistical Analysis in Climate Research. Cambridge University Press, 484 pp.

Voulgaris, G., and M. B. Collins, 2000: Sediment resuspension on beaches: Response to breaking waves. Mar. Geol., 67, 167-197.

Whipple, A. C., R. A. Luettich, and H. E. Seim, 2006: Measurements of Reynolds stress in a wind-driven lagoonal estuary. Ocean Dyn., 56, 169-185.

Wright, L. D., R. T. Guza, and A. D. Short, 1982: Dynamics of a high-energy dissipative surf zone. Mar. Geol., 45, 41-62.

Zhang, D., and T. Sunamura, 1990: Conditions for the occurrence of vortices induced by breaking waves. Coastal Eng. J., 33, $145-155$. 